\title{
IKK $\beta$ promotes metabolic adaptation to glutamine deprivation via phosphorylation and inhibition of PFKFB3
}

\author{
Michael A. Reid, ${ }^{1}$ Xazmin H. Lowman, ${ }^{1}$ Min Pan, ${ }^{1}$ Thai Q. Tran, ${ }^{1}$ Marc O. Warmoes, ${ }^{2}$ \\ Mari B. Ishak Gabra, ${ }^{1}$ Ying Yang, ${ }^{1}$ Jason W. Locasale, ${ }^{3}$ and Mei Kong ${ }^{1}$ \\ ${ }^{1}$ Department of Cancer Biology, Beckman Research Institute of City of Hope Cancer Center, Duarte, California 91010, USA; \\ ${ }^{2}$ Division of Nutritional Sciences, Cornell University, Ithaca, New York 14853, USA; ${ }^{3}$ Department of Pharmacology and Cancer \\ Biology, Duke University School of Medicine, Durham, North Carolina 27708, USA
}

\begin{abstract}
Glutamine is an essential nutrient for cancer cell survival and proliferation. Enhanced utilization of glutamine often depletes its local supply, yet how cancer cells adapt to low glutamine conditions is largely unknown. Here, we report that IKB kinase $\beta$ (IKK $\beta$ ) is activated upon glutamine deprivation and is required for cell survival independently of NF-кB transcription. We demonstrate that IKK $\beta$ directly interacts with and phosphorylates 6-phosphofructo-2-kinase/fructose-2,6-biphosphatase isoform 3 (PFKFB3), a major driver of aerobic glycolysis, at Ser269 upon glutamine deprivation to inhibit its activity, thereby down-regulating aerobic glycolysis when glutamine levels are low. Thus, due to lack of inhibition of PFKFB3, IKK $\beta$-deficient cells exhibit elevated aerobic glycolysis and lactate production, leading to less glucose carbons contributing to tricarboxylic acid (TCA) cycle intermediates and the pentose phosphate pathway, which results in increased glutamine dependence for both TCA cycle intermediates and reactive oxygen species suppression. Therefore, coinhibition of IKK $\beta$ and glutamine metabolism results in dramatic synergistic killing of cancer cells both in vitro and in vivo. In all, our results uncover a previously unidentified role of IKK $\beta$ in regulating glycolysis, sensing low-glutamine-induced metabolic stress, and promoting cellular adaptation to nutrient availability.
\end{abstract}

[Keywords: metabolic stress; aerobic glycolysis; glutamine; IKK $\beta$; PFKFB3]

Supplemental material is available for this article.

Received February 10, 2016; revised version accepted July 28, 2016.

Driven by oncogenic signaling, cancer cells rapidly take up glucose and glutamine to support the bioenergetic demands of proliferation (Gao et al. 2009; Boroughs and DeBerardinis 2015). In contrast to normal cells, cancer cells divert glucose away from the tricarboxylic acid (TCA) cycle by converting a majority of their glucosederived pyruvate to lactate, a phenomenon known as the Warburg effect or aerobic glycolysis (Lunt and Vander Heiden 2011). Because of this, cancer cells rely on glutamine to replenish TCA cycle intermediates through anaplerosis. Glutamine is metabolized to glutamate by glutaminase, which enters the mitochondria and is converted to a-ketoglutarate before continuing into a truncated TCA cycle (DeBerardinis et al. 2008). Besides replenishing TCA cycle intermediates, glutamine is important for highly proliferative cells, as it donates nitrogen to maintain pools of nonessential amino acids and also is a precursor for glutathione (GSH), a major cellular antioxidant (DeBerardinis et al. 2007). As aerobic

Corresponding author: mekong@coh.org

Article published online ahead of print. Article and publication date are online at http://www.genesdev.org/cgi/doi/10.1101/gad.287235.116. glycolysis increases, more glutamine-derived GSH is produced to combat reactive oxygen species (ROS) generated by enhanced metabolism and proliferation (Le et al. 2012).

As tumors grow, increased glutamine demand and glutamine metabolism often leads to depletion of local supplies (Roberts and Frankel 1949; Kamphorst et al. 2015). This causes periods of glutamine deprivation as cancer cells wait for new vasculature to develop. Surprisingly, cancer cells are able to survive glutamine-restricted environments, which suggests that tumors have developed adaptations to this metabolic stress. We recently reported a cell cycle arrest checkpoint used by tumor cells in response to low glutamine levels, but other mechanisms may also contribute to cell survival in this context, such as alternative metabolism of available nutrients (Reid et al. 2013). For example, a recent report showed that, in

(C) 2016 Reid et al. This article is distributed exclusively by Cold Spring Harbor Laboratory Press for the first six months after the full-issue publication date (see http://genesdev.cshlp.org/site/misc/terms.xhtml). After six months, it is available under a Creative Commons License (Attribution-NonCommercial 4.0 International), as described at http://creativecommons.org/licenses/by-nc/4.0/. 
highly glycolytic cells, the majority of TCA cycle carbons is derived from glutamine, but, when aerobic glycolysis was reduced, less glutamine contributed to TCA cycle intermediates, which decreased glutamine dependence (Le et al. 2012). Of particular interest, glutamine starvation reduces glycolytic flux; however, the molecular mechanisms mediating this remain unknown (Wong et al. 2004). Thus, inhibition of glycolytic flux may decrease glutamine dependence and contribute to cell survival under low-glutamine conditions.

The IкB kinase $\beta$ (IKK $\beta$ ) is well studied as a master regulator of cell survival and the inflammatory response (Comb et al. 2011, 2012; Oeckinghaus et al. 2011). Upon stimulation, IKK $\beta$ phosphorylates the IкB proteins, leading to their degradation and subsequent activation of NF- $\mathrm{kB}$ transcription factors (Oeckinghaus et al. 2011). Besides initiating NF- $\mathrm{kB}$ transcriptional activity, IKK $\beta$ directly phosphorylates numerous other substrates, such as TSC1, BAD, p85a, $\beta$-Catenin, and IRF5 kinase (Lamberti et al. 2001; Lee et al. 2007; Comb et al. 2012; Yan et al. 2013; Ren et al. 2014). Recently, IKK $\beta$ has emerged as a sensor of oxidative and metabolic stress. For example, IKK $\beta$ is activated by ROS and contributes to cell survival (Storz and Toker 2003). In addition, IKK $\beta-N F-\kappa B$ promotes cell survival upon glucose starvation via up-regulation of mitochondrial respiration (Mauro et al. 2011) and also modulates glucose metabolism through expression of GLUT3 (Kawauchi et al. 2008). Furthermore, acute leucine starvation activates IKK $\beta$, which phosphorylates and inhibits the p85a subunit of PI3K, leading to a downstream adaptation that is independent of NF- $\mathrm{kB}$ transcription (Comb et al. 2012). Moreover, multiple inducers of autophagy, including nutrient depletion, trigger the activation of IKK $\beta$ (Criollo et al. 2010). However, whether IKK $\beta$ is activated in response to prolonged glutamine deprivation, which is a major metabolic stress that elevates cellular ROS levels, has not been explored.

Isoform 3 of the bifunctional enzyme 6-phosphofructo2-kinase/fructose-2,6-biphosphatase (PFKFB3) is overexpressed in numerous cancers and has emerged recently as a driving force of aerobic glycolysis (Atsumi et al. 2002; Ros et al. 2012). PFKFBs facilitate the conversion of fructose-6-phosphate (F-6-P) to fructose-2,6-bisphosphate $(\mathrm{F}-2,6-\mathrm{BP})$ as well as the reverse reaction. PFKFB3 has the highest kinase to phosphatase ratio of the PFKFB family, favoring F-2,6-BP production 700-fold (Sakakibara et al. 1997). Mechanistically, F-2,6-BP allosterically activates phosphofructokinase 1 (PFK1), which promotes the conversion of F-6-P to fructose-1,6-bisphosphate (F-1,6$\mathrm{BP}$ ), a rate-limiting step in glycolysis (Van Schaftingen et al. 1980). PFK1 is allosterically inhibited by downstream glycolytic products phosphoenolpyruvate and ATP, but PFKFB3-produced F-2,6-BP can override this inhibition, thus increasing the glycolytic capacity of the cell (Van Schaftingen et al. 1981). Consistent with the fact that PFKFB3 promotes the Warburg effect, inhibition of PFKFB3 results in decreased glycolytic activity and lactate production (Calvo et al. 2006; Schoors et al. 2014).
In this study, we found that IKK $\beta$ activity is enhanced under glutamine starvation, and its activation is essential for cell survival under low glutamine. Using a proteomics and biochemical approach, we found that IKK $\beta$ phosphorylates PFKFB3 at Ser269, which decreases its activity. Consistently, IKK $\beta$ knockdown leads to increased PFKFB3 activity, which causes enhanced aerobic glycolysis, lactate production, and glutamine dependence. Using tracer-labeling experiments, we demonstrated that IKK $\beta$ deficient cells convert less of their glucose into TCA cycle intermediates yet have more overall intermediates due to increased glutamine uptake. Consequently, IKK $\beta$-deficient cells are more sensitive to glutamine depletion, and combinatorial targeting of IKK $\beta$ and glutamine metabolism dramatically sensitizes cancer cells to glutaminase inhibitor treatment both in vitro and in vivo.

\section{Results}

\section{$I K K \beta$ is required for cell survival upon glutamine deprivation, independent of NF- $\kappa B$ transcription}

Recently, IKK $\beta$ has emerged as a sensor of oxidative and metabolic stress (Storz and Toker 2003; Criollo et al. 2010). To investigate whether glutamine deprivation, which is a major metabolic stress that elevates cellular ROS levels (Reid et al. 2013), can lead to the activation of IKK $\beta, 293 \mathrm{~T}$ cells were transiently transfected with Flag-tagged IKK $\beta$ and cultured in complete medium or glutamine-free medium for $24 \mathrm{~h}$ followed by immunoprecipitation with anti-Flag conjugated agarose. TNFa treatment (15 $\mathrm{min}$ ) was used as a positive control. We found that IKK $\beta$ is phosphorylated at Ser177 in complete medium conditions, and glutamine starvation led to robust IKK $\beta$ Ser177 phosphorylation, similar to TNF $\alpha$ treatment (Fig. 1A). Moreover, we observed similar IKK $\beta$ phosphorylation in HeLa cells upon glutamine deprivation (Supplemental Fig. S1A). Interestingly, no phosphorylation was found in IKKa purified by anti-Flag-conjugated beads when glutamine levels were depleted (Supplemental Fig. S1B). Because IKK $\beta$ transautophosphorylates (Polley et al. 2013), we used the same conditions and subjected Flag-IKK $\beta$ immunoprecipitates to a ${ }^{32} \mathrm{P}$-ATP in vitro kinase assay and again found that $\operatorname{IKK} \beta$ is phosphorylated in complete medium and is further activated in response to glutamine deprivation (Fig. 1B). It is well established that IKK $\beta$ is activated in response to ROS accumulation (Schoonbroodt et al. 2000; Storz and Toker 2003; Takada et al. 2003; Storz et al. 2004; Gloire et al. 2006), and we reported that glutamine deprivation leads to increased cellular ROS (Reid et al. 2013). Thus, in order to determine whether low-glutamine-induced IKK $\beta$ activation was ROS-dependent, cells cultured in low glutamine were supplemented with antioxidant $N$-acetyl- $L$-cysteine (NAC), which was sufficient to prevent IKK $\beta$ phosphorylation upon glutamine starvation (Fig. 1C). We next examined the activation of the IKK $\beta$ signaling pathway upon glutamine limitation in mouse embryonic fibroblasts (MEFs) and HT1080 cells. In addition to IKK $\beta$ phosphorylation, we observed p65 phosphorylation and IкB degradation, 
IKK $\beta$ phosphorylates PFKFB3 to reduce glycolysis

A

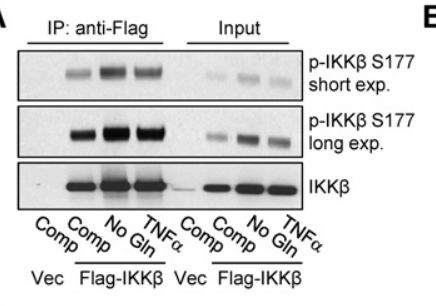

C

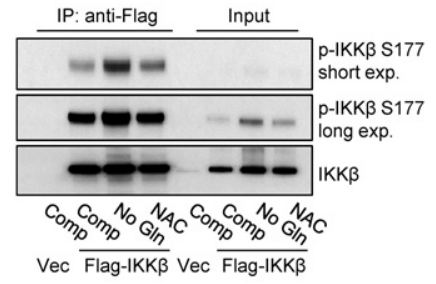

F

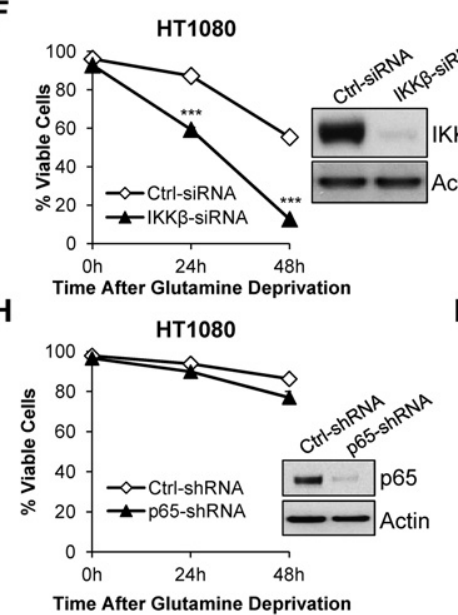

B

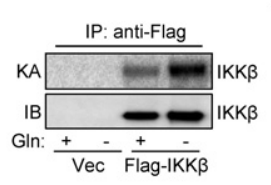

E

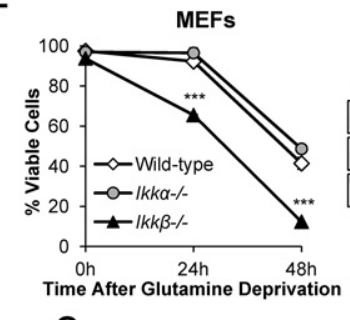

G
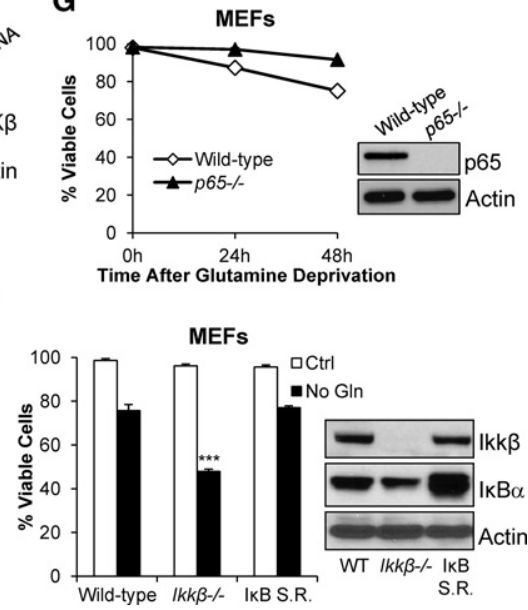

D
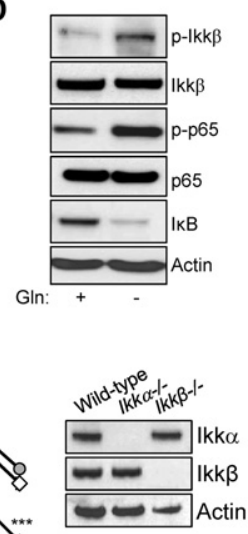

$\rightarrow-$ Actin$$
\text { . }
$$

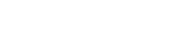


did observe p65 transcriptional activity upon glucose starvation and TNFa treatment (Supplemental Fig. S1D). Since p65 is not the only NF- $\mathrm{B}$ transcription factor, we overexpressed the superrepressive form of IкBa, a dominant-negative mutant that prevents activity of all NF- $\mathrm{BB}$ family members, in wild-type MEFs using retrovirus (Lin et al. 1996) and found that these cells displayed viability similar to that of wild-type MEFs under glutamine starvation (Fig. 1I). Taken together, these data suggest that low-glutamine-induced ROS accumulation activates IKK $\beta$ to promote cell survival independent of NF- $\mathrm{B}$ transcription.

\section{$I K K \beta$ is a PFKFB3 kinase}

To identify the downstream substrate of IKK $\beta$ under lowglutamine conditions, $293 \mathrm{~T}$ cells were transiently transfected with Flag-tagged IKK $\beta$ and starved of glutamine for $24 \mathrm{~h}$ followed by immunoprecipitation using antiFlag-conjugated agarose to purify proteins interacting with IKK $\beta$. The potential binding partners were further eluted with Flag peptide and identified by protein mass spectrometric peptide sequencing. Known IKK $\beta$-interacting proteins such as IKKa, NEMO, CDC37, and PP1 were identified, thus validating the approach (Fig. 2A). Of particular interest, we found that PFKFB3 interacted with IKK $\beta$ (Fig. 2A). To confirm our mass spectrometry (MS) findings, we transiently coexpressed Flag-tagged IKK $\beta$ and V5-tagged PFKFB3 in 293T cells followed by immunoprecipitation with anti-Flag or anti-V5 antibody and found that IKK $\beta$ and PFKFB3 bind together (Fig. 2B,C). Importantly, we found increased association between IKK $\beta$ and PFKFB3 upon glutamine starvation (Fig. 2D). Although glycolysis occurs mostly in the cytosol and although PFKFB3 is a major regulator of glycolysis, recent reports have indicated cytosolic and nuclear roles for PFKFB3 (Yalcin et al. 2014; Domenech et al. 2015). This prompted us to examine the colocalization of IKK $\beta$ and PFKFB3 using immunofluorescence on the endogenous proteins. We indeed found a robust amount of PFKFB3 in the cytosol and nucleus and a strong colocalization of IKK $\beta$ and PFKFB3 in both compartments (Supplemental Fig. S2A). Moreover, we fractionated HT1080 cells and confirmed our immunofluorescence findings that both
A

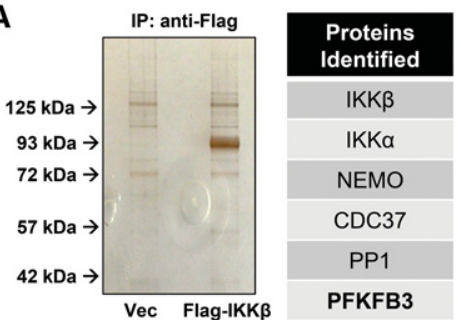

C

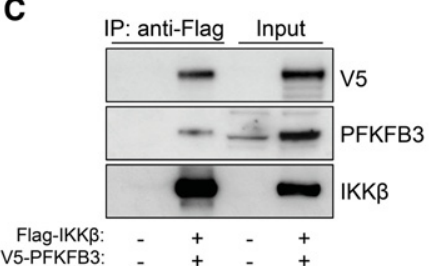

E

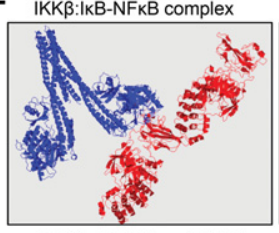

PDB: 4KIK and $1 \mathrm{NFI}$

G

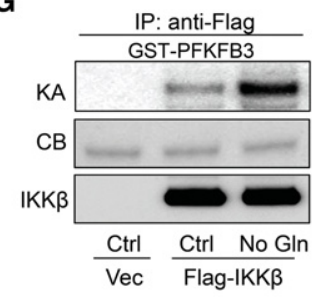

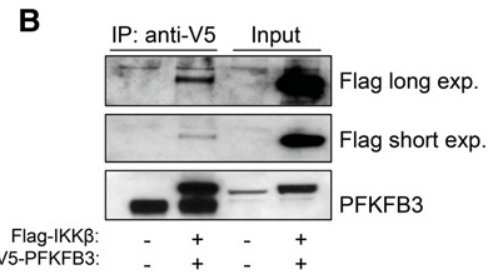

D

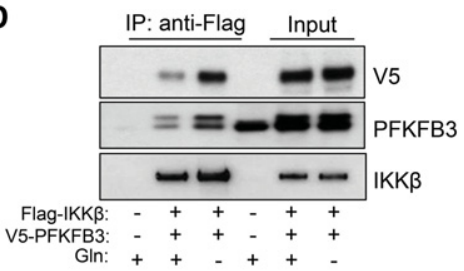

$\mathbf{F}$

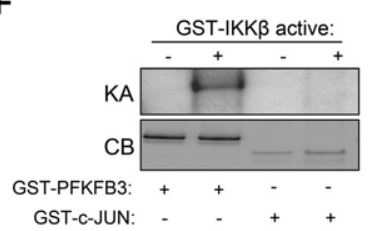

PDB: 4KIK and 2DWO

H

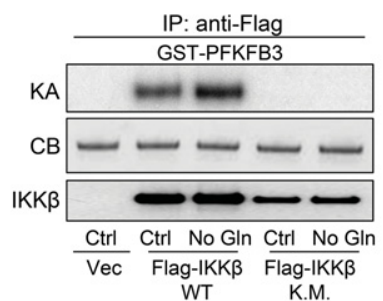

Figure 2. IKK $\beta$ is a PFKFB3 kinase. $(A)$ Silver-stained gel of eluates from 24-h glutamine-starved 293T cells expressing vector $(\mathrm{Vec})$ or Flag-IKK $\beta$. The bands unique to the Flag-IKK $\beta$ eluates were identified by mass spectrometric analysis. $(B, C) 293$ T cells ectopically coexpressing Flag-IKK $\beta$ and V5-PFKFB3 were immunoprecipitated with anti-V5 $(B)$ or anti-Flag $(C)$ antibody followed by immunoblotting with the indicated antibodies (15\% input). (D) $293 \mathrm{~T}$ cells ectopically coexpressing Flag-IKK $\beta$ and V5-PFKFB3 were cultured in complete or glutamine-free medium for $24 \mathrm{~h}$ followed by immunoprecipitation with antiFlag antibody and immunoblotting with the indicated antibodies (15\% input). (E, left panel) PRISM structure analysis for the predicted interaction between IKK $\beta$ (Protein Data Bank [PDB]: 4KIK) and the IкB $\alpha-$ NFאB complex (PDB: 1NFI). (Right panel) PRISM structure analysis for the predicted interaction between IKK $\beta$ (PDB: 4KIK) and PFKFB3 (PDB: 2DWO). $(F)^{32} \mathrm{P}$-ATP in vitro kinase assay (KA) was performed using $0.2 \mu \mathrm{g}$ of recombinant active GST-IKK $\beta$ with 2 $\mu \mathrm{g}$ of recombinant GST-PFKFB3 or $2 \mu \mathrm{g}$ of recombinant GST-c-JUN followed by SDS-PAGE separation and autoradiograph exposure. Coomassie blue (CB) staining confirmed loading in the absence of the kinase assay band. (G) 293 T cells ectopically expressing Flag-IKK $\beta$ were cultured for $24 \mathrm{~h}$ in complete medium or glutamine-free medium followed by immunoprecipitation with anti-Flag-conjugated agarose. ${ }^{32} \mathrm{P}$ ATP in vitro kinase assay was performed on immunoprecipitates incubated with $2 \mu \mathrm{g}$ of recombinant GSTPFKFB3 followed by SDS-PAGE separation and autoradiograph exposure. $(H) 293$ T cells ectopically expressing Flag-IKK $\beta$ (wild type) or the kinase-inactive mutant Flag-IKK $\beta$ (K.M.) were cultured for $24 \mathrm{~h}$ in complete medium or glutamine-free medium followed by immunoprecipitation with anti-Flag-conjugated agarose. ${ }^{32} \mathrm{P}$-ATP in vitro kinase assay was performed on immunoprecipitates incubated with $2 \mu \mathrm{g}$ of recombinant GST-PFKFB3 followed by SDS-PAGE separation and autoradiograph exposure. 
IKK $\beta$ and PFKFB3 are in the nucleus and cytosol (Supplemental Fig. S2B). In order to gain insight into how these proteins interact, we used protein interactions by structural matching (PRISM) (Tuncbag et al. 2011; Baspinar et al. 2014) and found that PFKFB3 is predicted to interact with the catalytic region of IKK $\beta$ in a fashion similar to IאBa, a well-known IKK $\beta$ substrate (Fig. 2E). Therefore, we hypothesized that PFKFB3 is phosphorylated by IKK $\beta$. To test this hypothesis, we performed a ${ }^{32} \mathrm{P}$-ATP in vitro kinase assay using recombinant GST-PFKFB3 with and without constitutively active GST-IKK $\beta$. Indeed, active IKK $\beta$ was sufficient to phosphorylate PFKFB3 but not the JNK substrate c-JUN, as expected (Fig. 2F). Furthermore, we tested whether immunoprecipitated FlagIKK $\beta$ from cells cultured in complete or glutamine-free medium could phosphorylate GST-PFKFB3 in a ${ }^{32} \mathrm{P}-\mathrm{ATP}$ in vitro kinase assay and found that, consistent with IKK $\beta$ phosphorylation levels (Fig. 1A), IKK $\beta$ phosphorylated PFKFB3 at low levels in complete medium conditions and robustly when cells are starved of glutamine (Fig. 2G). To exclude the possibility that we copurified a contaminating kinase, we performed the same experiment using a kinase-inactive Flag-IKK $\beta$ and found no PFKFB3 phosphorylation (Fig. 2H). Moreover, we used IKK $\beta$-specific inhibitor TPCA-1 and found that this greatly diminished phosphorylation of PFKFB3 (Supplemental Fig. S2C). Taken together, we identified PFKFB3 as a putative IKK $\beta$ substrate that is phosphorylated at low levels in proliferating cells and higher levels when cells are deprived of glutamine.

\section{IKK $\beta$ phosphorylates PFKFB3 at Ser269}

Next, we wanted to identify which residue on PFKFB3 is phosphorylated by IKK $\beta$. To do this, we performed an in vitro kinase assay using recombinant constitutively active GST-IKK $\beta$ and GST-PFKFB3 followed by protein mass spectrometric phosphopeptide mapping and found that PFKFB3 was phosphorylated on Ser269 (Fig. 3A). Strikingly, the phosphopeptide that we identified matched the consensus IKK $\beta$ phospho-motif and shared high sequence similarity with other IKK $\beta$ substrates such as IкBa, p105, $\beta$-Catenin, FOXO3a, and TSC1 (Fig. 3B). To further investigate Ser269 phosphorylation, we raised an antibody against this site and performed an in vitro kinase assay followed by immunoblotting and found that Ser269 was indeed phosphorylated by active IKK $\beta$ (Fig. 3C). We further validated this antibody by performing the same experiment on S269A mutant PFKFB3 (Supplemental Fig. S3A). Intriguingly, PFKFB4 has a proline in place of serine in the corresponding sequence homology with PFKFB3 (Fig. $3 \mathrm{D})$. With a ${ }^{32} \mathrm{P}$-ATP in vitro kinase assay, we found that active IKK $\beta$ phosphorylated GST-IкB $\alpha$ and GST-PFKFB3 but was unable to phosphorylate recombinant GSTPFKFB4 (Fig. 3E). To conclusively validate the specificity of the PFKFB3 Ser269 phosphosite, we performed a ${ }^{32} \mathrm{P}$ ATP in vitro kinase assay using wild-type and S269A mutant GST-PFKFB3. We found that only wild-type PFKFB3 was highly phosphorylated by active IKK $\beta$, while phosphorylation of S269A was significantly diminished (Fig.
$3 F)$, suggesting that Ser269 is the major site that is phosphorylated by IKK $\beta$. To test whether endogenous PFKFB3 is phosphorylated at Ser269, PFKFB3 was immunoprecipitated from HT1080 cells cultured in complete or glutamine-free medium followed by immunoblotting. Indeed, PFKFB3 is phosphorylated at Ser269 endogenously at low levels in proliferating cells in complete medium and at high levels in cells starved of glutamine (Fig. 3G). Interestingly, we further found that other IKK $\beta$ stimuli, including LPS and TNFa, also led to PFKFB3 Ser269 phosphorylation (Supplemental Fig. S3B,C). To examine whether PFKFB3 Ser269 occurs in vivo, we treated HT1080 mouse xenograft tumors with glutaminase inhibitor 6-diazo-5-oxo-L-norleucine (DON) and found that, compared with PBS control, DON-treated tumors showed significant PFKFB3 Ser269 phosphorylation (Fig. 3H). Importantly, using HT1080 cells stably expressing control or IKK $\beta$-shRNA, we found that PFKFB3 Ser269 phosphorylation is IKK $\beta$-dependent (Fig. 3I).

\section{PFKFB3 Ser269 phosphorylation reduces its activity}

We then sought to determine how IKK $\beta$ phosphorylation affected PFKFB3. We first examined PFKFB3 function by performing a PFKFB3 activity assay on HT1080 cells expressing control or IKK $\beta$ shRNA and found that IKK $\beta$ knockdown cells have a twofold increase in PFKFB3 activity, suggesting that IKK $\beta$ negatively regulates PFKFB3 (Fig. 4A). Moreover, using liquid chromatography high-resolution MS (LC-HR-MS), we found that, compared with control cells, IKK $\beta$ knockdown cells exhibit threefold higher levels of F-1,6-BP, the major product of PFKFB3-induced PFK1 activity (Fig. 4B). To investigate how Ser269 phosphorylation affects PFKFB3 activity, we first depleted endogenous PFKFB3 from HT1080 cells using shRNA (Fig. 4C, lanes 1,2). We then ectopically expressed V5-tagged wild-type, Ser269Ala (S269A) mutant, or Ser269Asp (S269D) mutant PFKFB3 in PFKFB3-shRNA cells (Fig. 4C, lanes 3-5). Using these cells for a PFKFB3 activity assay, we found that cells expressing S269A PFKFB3 had 65\% more activity, while S269D PFKFB3 displayed 80\% less activity than cells expressing wild-type PFKFB3 (Fig. 4D), providing strong evidence that IKK $\beta$-dependent PFKFB3 Ser269 phosphorylation inhibits its activity. Furthermore, we characterized the effect that S269A and S269D mutant PFKFB3 had on aerobic glycolysis and found that S269A mutant PFKFB3-expressing cells had significantly increased glucose uptake and lactate production compared with wild type, while S269D mutant PFKFB3 showed much less (Fig. 4E). Intriguingly, we found that glutamine starvation reduced the total protein level of PFKFB3 in an IKK $\beta$-dependent manner (Fig. 3G,I, inputs). Moreover, it has been reported that PFKFB3 is regulated by the SCF $\beta-T R C P$-ubiquitin ligase complex (Colombo et al. 2011; Duan and Pagano 2011), which often targets IKK $\beta$ phosphorylation substrates (Winston et al. 1999). To further investigate whether Ser269 played a role in PFKFB3 protein stability, we ectopically expressed wild type or the S269A mutant in HT1080 and $293 T$ cells overnight and found a striking increase in 


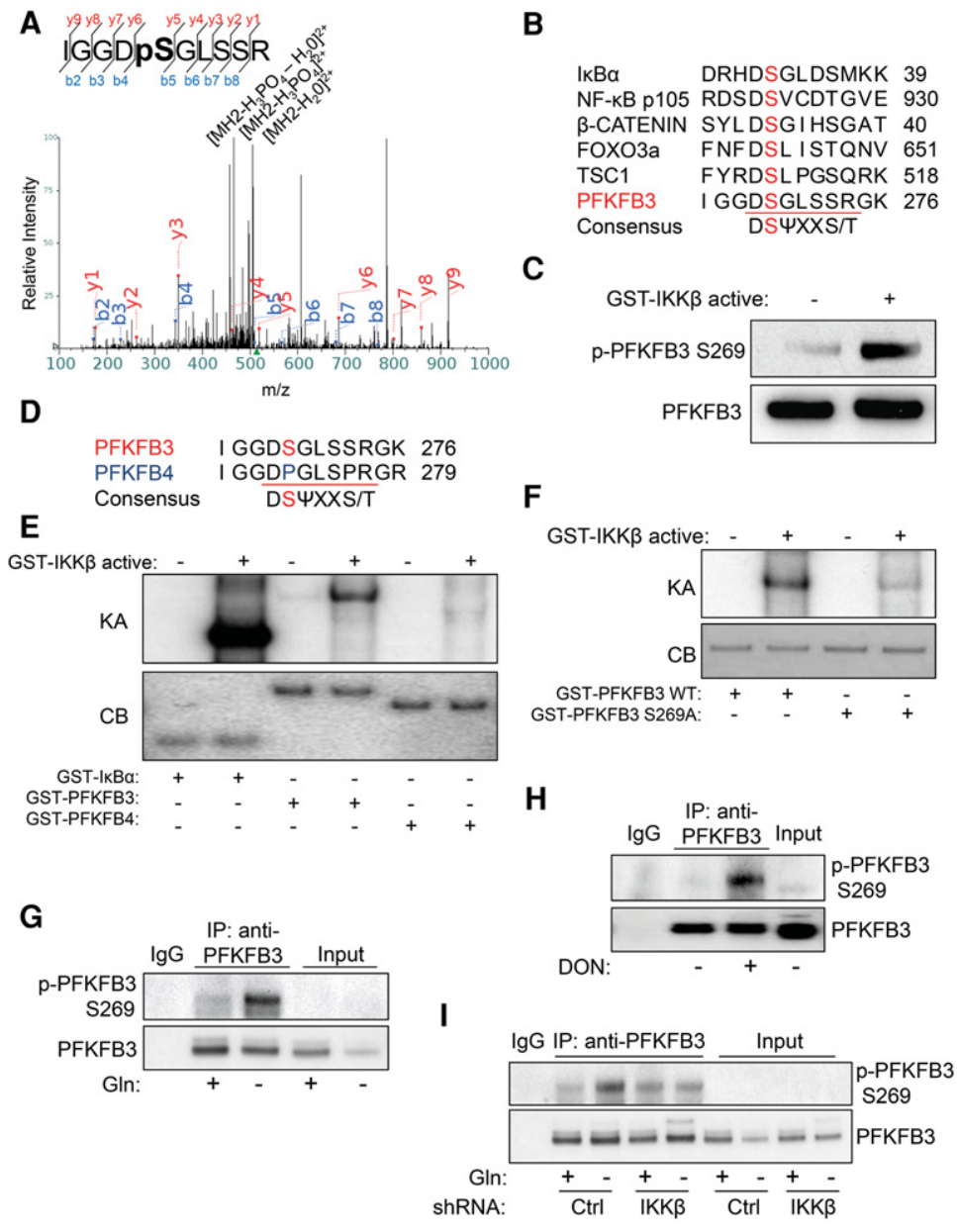

Figure 3. IKK $\beta$ phosphorylates PFKFB3 at Ser269. (A) Cold kinase assay using recombinant active GSTIKK $\beta$ and recombinant GST-PFKFB3 was performed followed by SDS-PAGE separation and phosphopeptide mapping. Mass spectra of identified phosphopeptide IGGD ${ }^{\mathrm{p}}$ SGLSSR are presented. $(B)$ Sequence homology between the consensus IKK $\beta$ phospho-motif, known IKK $\beta$ substrates, and PFKFB3. (C) Cold kinase assay using recombinant active GST-IKK $\beta$ and recombinant GSTPFKFB3 was performed followed by immunoblotting with the indicated antibodies. PFKFB3 phospho-Ser269 antibody was raised against the antigen LGGRIGGDpS-GLSSR. $(D)$ Sequence homology between the consensus IKK $\beta$ phospho-motif, PFKFB3, and PFKFB4. $(E)^{32} \mathrm{P}$ ATP in vitro kinase assay (KA) was performed using 0.2 $\mu \mathrm{g}$ of recombinant active GST-IKK $\beta$ with $0.5 \mu \mathrm{g}$ of recombinant GST-IкB $\alpha, 2 \mu \mathrm{g}$ of recombinant GST-PFKFB3, or 2 $\mu \mathrm{g}$ of recombinant GST-PFKFB4 followed by SDS-PAGE separation and autoradiograph exposure. Coomassie blue (CB) staining confirmed loading in the absence of the kinase assay band. $(F)^{32} \mathrm{P}$-ATP in vitro kinase assay (KA) was performed using $0.2 \mu \mathrm{g}$ of recombinant active GST-IKK $\beta$ with $2 \mu \mathrm{g}$ of recombinant GST-PFKFB3 wild type or $2 \mu \mathrm{g}$ of recombinant GST-PFKFB3 S269A followed by SDS-PAGE separation and autoradiograph exposure. Coomassie blue (CB) staining confirmed loading in the absence of the kinase assay band. (G) HT1080 cells were cultured for $48 \mathrm{~h}$ in complete medium or glutamine-free medium followed by immunoprecipitation with anti-PFKFB3 antibody; immunoblotting was performed with the indicated antibodies (15\% input). (H) Athymic (nude) mice were injected subcutaneously with $2 \times 10^{6}$ HT1080 cells. Mice were treated with 10 $\mathrm{mg} / \mathrm{kg}$ PBS or DON three times per week for $2 \mathrm{wk}$; tumors were harvested, followed by lysis and immunoprecipitation with anti-PFKFB3 antibody and immunoblotting with the indicated antibodies $125 \%$

input). (I) HT1080 cells transduced with either control (Ctrl) or IKK $\beta$ shRNA were cultured for $24 \mathrm{~h}$ in complete medium or glutamine-free medium followed by immunoprecipitation with anti-PFKFB3 antibody; immunoblotting was performed with the indicated antibodies (15\% input).

protein level of the S269A mutant, suggesting that Ser269 phosphorylation reduces PFKFB3 stability (Fig. 4F). Taken together, these data demonstrate that PFKFB3 Ser269 phosphorylation reduces enzymatic activity and protein stability.

\section{IKK $\beta$ down-regulates aerobic glycolysis through PFKFB3 inhibition}

Because PFKFB3 is a major regulator of the Warburg effect (Almeida et al. 2010), we hypothesized that IKK $\beta$-deficient cells, which have hyperactive PFKFB3, would have increased aerobic glycolysis. To test this, we cultured wildtype and $I k k \beta^{-1-}$ MEFs and control and IKK $\beta$ shRNA HT1080 cells in complete medium for $24 \mathrm{~h}$ to allow sufficient growth and nutrient use. Consistently, we found that genetic ablation of IKK $\beta$ led to increased glucose uptake and lactate production (Fig. 5A,B). To further evaluate the glycolytic capacity, we measured the extracellular acidification rate (ECAR) and found that IKK $\beta$-deficient cells have increased glycolytic flux, consistent with the observed increased glucose uptake and lactate production (Fig. 5C,D). In order to determine whether the increased aerobic glycolysis observed in IKK $\beta$-deficient cells was due to increased PFKFB3 activity, we stably knocked down both IKK $\beta$ and PFKFB3 in HT1080 cells (Fig. 5E). We found that knockdown of PFKFB3 was sufficient to rescue the increased aerobic glycolysis found in IKK $\beta$-deficient cells as glucose uptake, lactate production, and glycolytic flux were restored (Fig. 5F,G). It was reported that NF-kB-dependent GLUT3 expression plays an important role in glycolysis (Kawauchi et al. 2008). To further test whether other potential mechanisms, such as GLUT3, could contribute to IKK $\beta$-regulated aerobic glycolysis, we knocked down GLUT3 in HT1080 cells; however, no significant difference in cell viability upon glutamine withdrawal was observed (Supplemental Fig. S4A). This was consistent with our observation that IKK $\beta$, but not NF-kB, plays a role in cell adaptation to low-glutamine conditions (Fig. 1E-I). These data demonstrate that IKK $\beta$ antagonizes aerobic glycolysis mainly through inhibition of PFKFB3. 
A

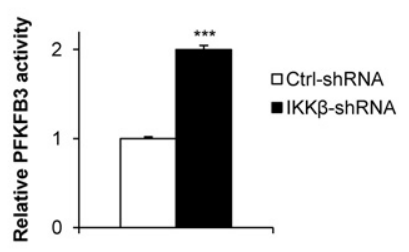

C

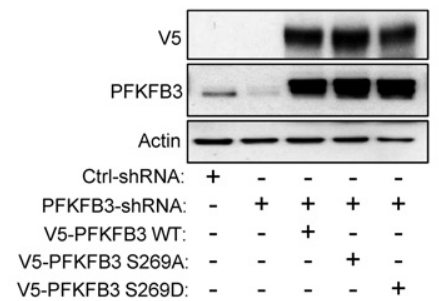

E
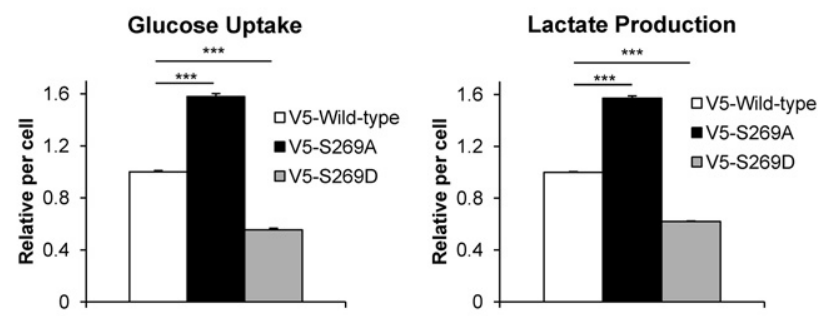

B

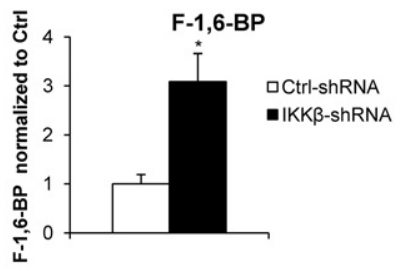

D

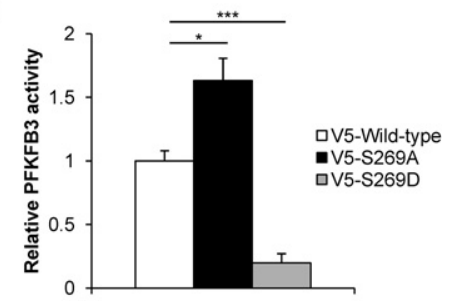

F

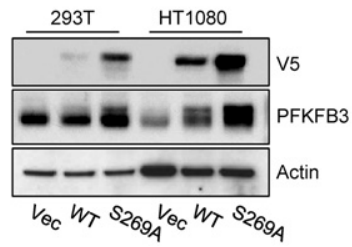

Enhanced aerobic glycolysis in IKK $\beta$-deficient cells leads to increased glutamine dependence for TCA cycle intermediates

To further elucidate how IKK $\beta$ affects glucose metabolism beyond inducing lactate production, we performed stable isotope tracer-labeling experiments by culturing control or IKK $\beta$ shRNA HT1080 cells for $6 \mathrm{~h}$ in medium containing universally labeled ${ }^{13} \mathrm{C}$-glucose (Fig. 6A). Metabolites were extracted and analyzed by LC-HR-MS. Consistent with our uptake experiments, these labeling experiments revealed a significant decrease in ${ }^{13} \mathrm{C}$-glucose remaining in IKK $\beta$ shRNA cells compared with control, which signifies that these cells used more glucose (Fig. 6B). Moreover, we observed increased glucose-derived lactate when IKK $\beta$ was knocked down (Fig. 6C). Consistent with PFKFB3 activity assays, we found that IKK $\beta$ knockdown cells have increased glucose-derived F-1,6-BP, providing further evidence that PFKFB3 activity is up-regulated in these cells (Fig. 6D). Strikingly, IKK $\beta$-deficient cells produced almost fivefold more pyruvate, the end product of glycolysis (Fig. 6E). Interestingly, very little of this glucose-derived pyruvate enters into the TCA cycle, as IKK $\beta$ knockdown cells have $\sim 20 \%$ less glucose-derived citrate and $\alpha$-keto-
Figure 4. PFKFB3 Ser269 phosphorylation reduces its activity. (A) PFKFB3 activity was measured in HT1080 cells transduced with either control (Ctrl) or IKK $\beta$ shRNA. OD values were normalized to the control shRNA reading. Data presented are mean \pm SEM of three independent experiments performed in duplicate. $(B)$ Metabolites were extracted from HT1080 cells transduced with either control (Ctrl) or IKK $\beta$ shRNA, and F-1,6-BP levels were measured by LC-HR-MS. Data presented are mean \pm SEM of three independent experiments performed in duplicate. (C) HT1080 cells were transduced with PFKFB3 shRNA to deplete endogenous PFKFB3 followed by ectopic expression of V5-tagged wild-type, S269A mutant, or S269D mutant PFKFB3 and blasticidin selection. Immunoblotting was performed with the indicated antibodies. $(D)$ PFKFB3 activity was measured in HT1080 cells depleted of endogenous PFKFB3 and ectopically expressing wild-type, S269A, or S269D PFKFB3. OD values from PFKFB3 shRNA cells expressing V5 vector control were subtracted from wild-type, S269A, and S269D OD values before being normalized to wild type. Data presented are mean \pm SEM of three independent experiments performed in duplicate. $(E)$ HT1080 cells depleted of endogenous PFKFB3 and ectopically expressing wild-type, S269A, or S269D PFKFB3 were cultured for $48 \mathrm{~h}$ in complete medium followed by glucose uptake and lactate production measurements using the Nova Bioprofile 100 analyzer. Metabolite levels per cell were normalized to wild type. Data presented are mean \pm SEM of three independent experiments performed in duplicate. $(F) 293 \mathrm{~T}$ and HT1080 cells were transduced with V5-tagged wild-type or mutant (S269A) PFKFB3. Forty-eight hours after transduction, cells were lysed, and immunoblotting was performed with the indicated antibodies. $\left(^{*}\right) P<0.05$; $\left({ }^{* * *}\right) P<0.005$, Student's $t$-test. glutarate (Fig. 6F,G). However, IKK $\beta$-deficient cells have increased total levels of unlabeled citrate and $\alpha$-ketoglutarate, which suggests that these cells may use glutamine for anaplerosis (Fig. 6H,I). Indeed, cells lacking IKK $\beta$ have increased glutamine uptake (Fig. 6J). Importantly, the increased glutamine uptake is PFKFB3-dependent because cells with knockdown of both IKK $\beta$ and PFKFB3 uptake glutamine at the same level as control shRNA cells (Fig. 6K). We reasoned that the increased glutamine uptake could explain why IKK $\beta$-deficient cells are more sensitive to glutamine starvation. To confirm this, we performed propidium iodide exclusion flow cytometry to measure the viability of control, IKK $\beta$, and IKK $\beta$-PFKFB3 shRNA cells and found that IKK $\beta$ knockdown cell viability in low glutamine is almost completely rescued by PFKFB3 ablation (Fig. 6L). Similarly, cells depleted of endogenous PFKFB3 and ectopically expressing S269A mutant PFKFB3 displayed increased glutamine uptake and sensitivity to glutamine starvation, demonstrating that the IKK $\beta$-deficient phenotype is largely driven by PFKFB3 Ser269 phosphorylation and not other IKK $\beta$-regulated metabolic processes (Supplemental Fig. S5A,B). Because increased aerobic glycolysis driven by hyperactive PFKFB3 in IKK $\beta$-deficient cells results in less glucose- 
A

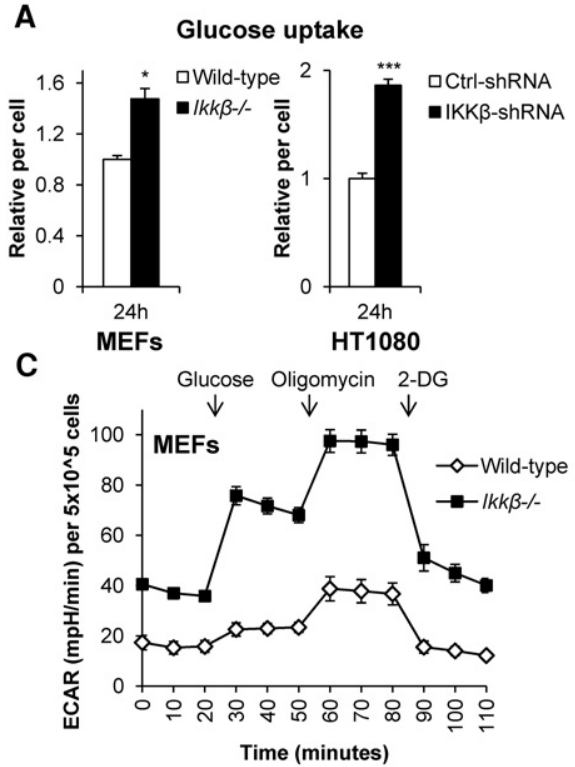

E

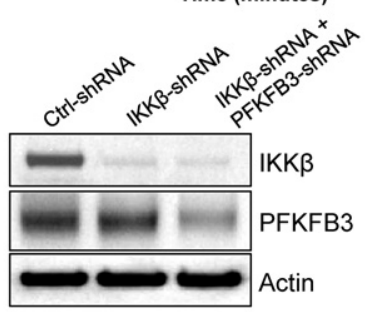

B Lactate production

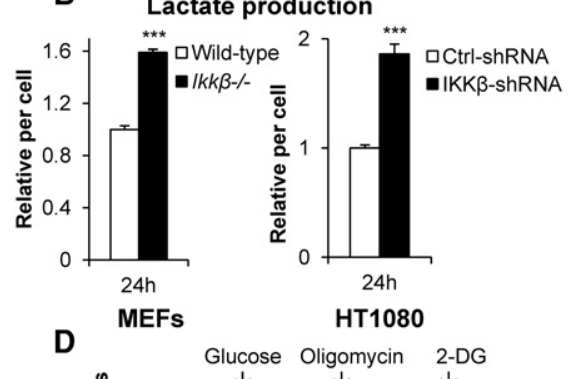

F Glucose uptake Lactate production

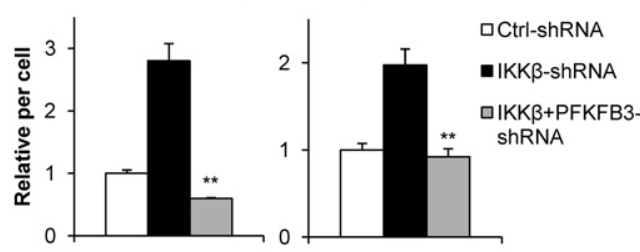

G

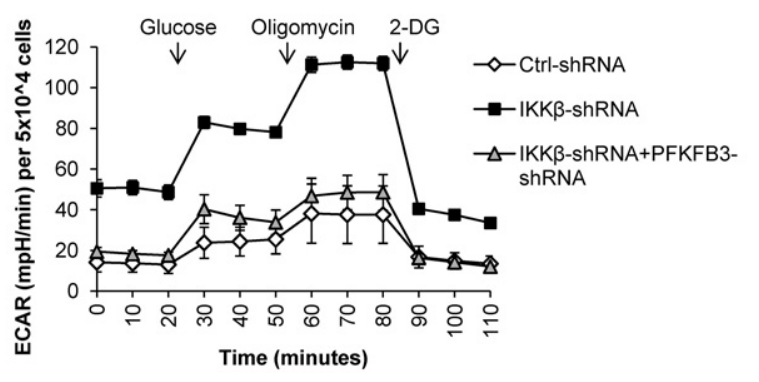

Figure 5. IKK $\beta$ down-regulates aerobic glycolysis through PFKFB3 inhibition. ( $A$, B) MEFs (wild type and $I k k \beta^{-1-}$ ) and HT1080 cells (control [Ctrl] and IKK $\beta$ shRNA) were cultured for $24 \mathrm{~h}$ in complete medium followed by glucose uptake and lactate production measurements using the Nova Bioprofile 100 analyzer. Metabolite levels per cell were normalized to wild-type or control shRNA. Data presented are mean \pm SEM of three independent experiments performed in duplicate. $(C, D)$ ECAR was measured in MEFs (wild type and $I k k \beta^{-I-}$ ) and HT1080 cells (control [Ctrl] and IKK $\beta$ shRNA) using the XF-24 Seahorse system. Data presented are mean \pm SEM of five independent experiments. $(E)$ HT1080 cells expressing IKK $\beta$ shRNA were transduced with PFKFB shRNA followed by cell lysis and immunoblotting with the indicated antibodies. $(F)$ HT1080 cells transduced with control (Ctrl), IKK $\beta$, or IKK $\beta$ and PFKFB3 shRNA were cultured for 24 $h$ in complete medium followed by glucose uptake and lactate production measurements using the Nova Bioprofile 100 analyzer. Metabolite levels per cell were normalized to control shRNA. Data presented are mean \pm SEM of three independent experiments performed in duplicate. $(G)$ ECAR was measured in cells transduced with control $(\mathrm{Ctrl}), \operatorname{IKK} \beta$, or IKK $\beta$ and PFKFB3 shRNA using the XF-24 Seahorse system. Data presented are mean \pm SEM of five independent experiments. $\left.{ }^{*}\right) P<0.05$; (**) $\left.P<0.01 ;{ }^{* * *}\right) P<0.005$, Student's $t$-test. derived carbons used by both the TCA cycle and the pentose phosphate pathway (Yamamoto et al. 2014), it is possible that the loss of glucose-derived carbons from both the pentose phosphate pathway and TCA cycle contributes to the loss of cell viability upon glutamine deprivation in IKK $\beta$-deficient cells. Indeed, IKK $\beta$ knockdown reduced cellular NADPH levels (Supplemental Fig. S5C), and while cell-permeable TCA cycle intermediate succinate or antioxidant GSH rescued cell viability at early time points, the combination of both agents synergistically rescued IKK $\beta$-deficient cell viability upon glutamine starvation at later time points (the viability of the combination group was $40 \%$, while the sum of both agents alone was $22 \%$ ) (Supplemental Fig. S5D). Taken together, these data support the hypothesis that highly glycolytic cells rely on glutamine to replenish TCA intermediates and antioxidants, and IKK $\beta$ acts to dampen aerobic glycolysis when cells experience periods of glutamine deprivation.
Inhibition of IKK $\beta$ sensitizes cancer cells and tumors to glutaminase inhibitor treatment

Targeting glutamine metabolism is quickly emerging as a viable option for numerous cancer types (Wise and Thompson 2010). One strategy for targeting glutamine metabolism is treating patients with glutaminase inhibitors such as DON, and these inhibitors have been used in clinical trials over the years; however, the trials have had little success due to cytotoxicity and adverse side effects (Sullivan et al. 1988; Earhart et al. 1990). Another explanation for the low efficacy of glutaminase inhibitors is adaptive pathways used by tumors to survive periods of glutamine starvation, suggesting that ablation of these adaptive pathways may enhance the effect, which could reduce the dose of glutaminase inhibitor required, thereby potentially alleviating off-target effects. To test whether disruption of the IKK $\beta$-PFKFB3 signaling axis could sensitize cancer cells to glutamine metabolism inhibition, we 
A

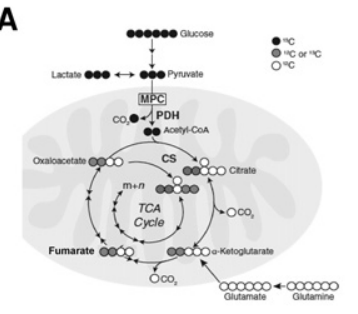

D ${ }^{13} \mathrm{C}$ glucose-derived F-1,6-BP

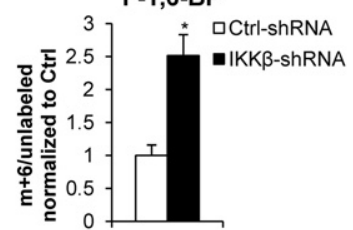

G

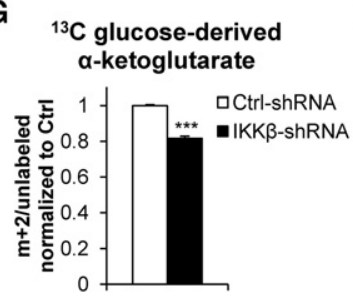

$\mathbf{J}$

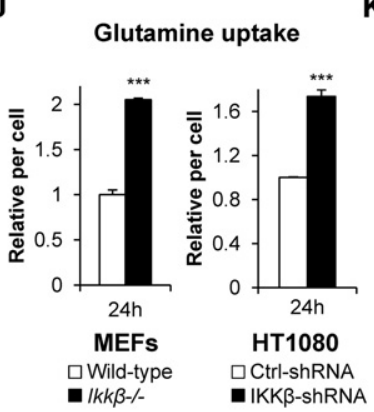

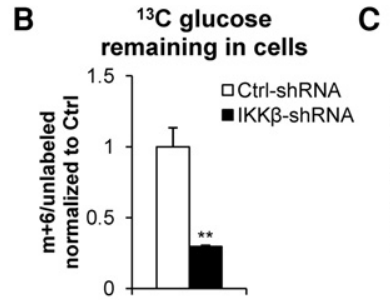

E
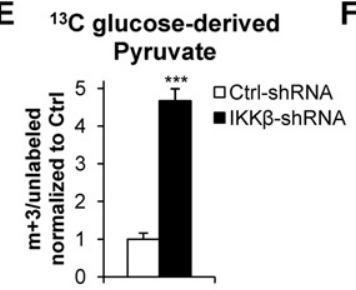

H

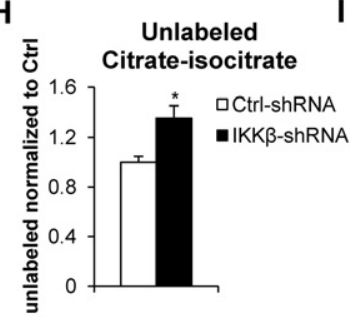

K

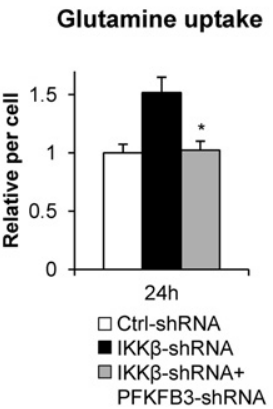

$\mathbf{L}$
${ }^{13} \mathrm{C}$ glucose-derived



F ${ }^{13} \mathrm{C}$ glucose-derived Citrate-isocitrate
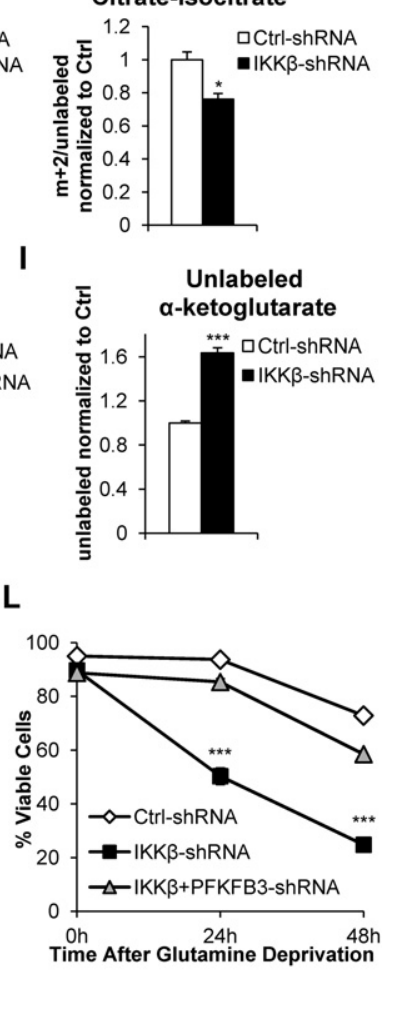

Figure 6. Enhanced aerobic glycolysis in IKK $\beta$-deficient cells leads to increased glutamine dependence for TCA cycle intermediates. (A) Schematic representation of ${ }^{13} \mathrm{C}$ glucose metabolism. $\mathrm{M}+\mathrm{n}$ refers to the number of ${ }^{13} \mathrm{C}$ found in each metabolite. $(B-G)$ HT1080 cells transduced with either control (Ctrl) or IKK $\beta$ shRNA were cultured for $6 \mathrm{~h}$ in medium containing universally labeled ${ }^{13} \mathrm{C}$-glucose followed by metabolite extraction and analysis using LC-HR-MS. Labeled metabolites were divided by unlabeled metabolites and then normalized to control shRNA levels. Data presented are mean \pm SEM of three independent experiments. $(H, I)$ HT1080 cells transduced with either control (Ctrl) or IKK $\beta$ shRNA were cultured for $6 \mathrm{~h}$ in medium containing universally labeled ${ }^{13} \mathrm{C}$-glucose followed by metabolite extraction and analysis using LCHR-MS. Unlabeled metabolites (i.e., metabolites not derived from glucose) were normalized to control shRNA levels. Data presented are mean \pm SEM of three individual experiments. (J) MEFs (wild type and $I k k \beta^{-/-}$) and HT1080 cells (control [Ctrl] and IKK $\beta$ shRNA) were cultured in complete medium for $24 \mathrm{~h}$ followed by glutamine uptake measurement using the Nova Bioprofile 100 analyzer. Metabolite levels per cell were normalized to wild-type or control shRNA. Data presented are mean \pm SEM of three independent experiments performed in duplicate. (K) HT1080 cells transduced with control (Ctrl), IKK $\beta$, or IKK $\beta$ and PFKFB3 shRNA were cultured in complete medium for $24 \mathrm{~h}$ followed by glutamine uptake measurement using the Nova Bioprofile 100 analyzer. Metabolite levels per cell were normalized to control shRNA. Data presented are mean \pm SEM of three independent experiments performed in duplicate. $(L)$ HT1080 cells transduced with control (Ctrl), IKK $\beta$, or IKK $\beta$ and PFKFB3 shRNA were cultured in glutamine-free medium, and viability was assessed by propidium iodide exclusion at the indicated time points. Data presented are mean \pm SEM of three independent experiments performed in duplicate. $(*) P<0.05 ;(* *)$ $P<0.01 ;\left(^{* * *}\right) P<0.005$, Student's $t$-test.

first determined whether treatment with the IKK $\beta$ inhibitor Bay 11-7082 (Bay) had any effect on cells under glutamine deprivation. Indeed, much like genetic ablation of IKK $\beta$, chemical inhibition using Bay dramatically sensitized HT1080 cells to low glutamine deprivation-induced cell death, but Bay had little effect on cells in complete medium (Fig. 7A). To investigate the possibility of Bay off-target effects, we treated IKK $\beta$-deficient HT1080 cells with the same dose as our previous experiment and observed no change in cell death in IKK $\beta$ knockdown cells under glutamine withdrawal, while the control cells were dramatically sensitized (Supplemental Fig. S6A). We then proceeded with the combination of Bay and DON and found striking synergistic killing of HT1080, glioblastoma U251, and triple-negative breast cancer MD-MBA-231 cells, suggesting that this combinational therapy can be applied to a broad range of cancer types (Fig. 7B-D). To test the combinational therapy in vivo, athymic (nude) mice were subcutaneously injected with $2 \times 10^{6} \mathrm{HT} 1080$ cells. Once tumors reached an average volume of $100 \mathrm{~mm}^{3}$, mice were placed in four groups and treated (intraperitoneally) three times per week with PBS control, $2.5 \mathrm{mg} / \mathrm{kg}$ Bay, $10 \mathrm{mg} / \mathrm{kg}$ DON, or $2.5 \mathrm{mg} / \mathrm{kg}$ Bay and $10 \mathrm{mg} / \mathrm{kg}$ DON combination, and a significant reduction in tumor growth was observed when the two drugs were administered together (Fig. 7E,F). Following completion of the study, tumors were harvested and homogenized followed by immunoprecipitation using anti-PFKFB3 antibody. Immunoblotting using anti-PFKFB3 p-Ser269 antibody revealed that animals treated with DON showed strong PFKFB3 Ser269 phosphorylation, while this phosphorylation was blocked in tumors of animals that received the combination of Bay and DON (Fig. 7G). Finally, we examined PFKFB3 Ser269 phosphorylation in human tissues using immunohistochemistry and found striking increases in the malignant tissues compared 
with healthy tissues, including breast, brain, and skin (Fig. $7 \mathrm{H})$. These data demonstrate that PFKFB3 phosphorylation at Ser269 is important for maintaining tumor growth when glutamine metabolism is inhibited or when local supplies are depleted, and disruption of PFKFB3 phosphorylation via IKK $\beta$ inhibition could be a strong adjuvant for established glutaminase inhibitor treatments.

\section{Discussion}

In this study, we uncovered a previously unidentified pathway by which IKK $\beta$ is activated as glutamine levels decrease and directly phosphorylates PFKFB3 to inhibit its activity, leading to decreased aerobic glycolysis and glutamine dependency. Thus, IKK $\beta$ deficiency and subsequent hyperactivation of PFKFB3 led to increased aerobic glycolysis and glutamine uptake (Figs. 5, 6), and the inability to adapt to low glutamine levels led to cell death (Figs.
$1,7)$. The relationship between highly glycolytic cells and their reliance on glutamine is quickly becoming well established (Vander Heiden et al. 2009; Le et al. 2012; Qing et al. 2012). For example, a recent report demonstrated that, in highly glycolytic cells, the majority of TCA cycle carbons are derived from glutamine, but, when aerobic glycolysis was reduced, less glutamine contributed to TCA cycle intermediates, which decreased glutamine dependence (Le et al. 2012). Intriguingly, it has been shown that high glutamine concentrations and glutamine-dependent anaplerosis led to increased glucose uptake and aerobic glycolysis (Kaadige et al. 2009). Moreover, glutamine depletion/repletion studies found that aerobic glycolysis is decreased in response to glutamine starvation (Wong et al. 2004). Our data are in agreement with these reports in that glutamine availability and aerobic glycolysis are tightly correlated, and a disconnect results in loss of cell viability.
A



C

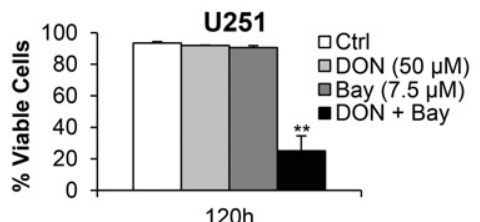

$\mathbf{E}$



G

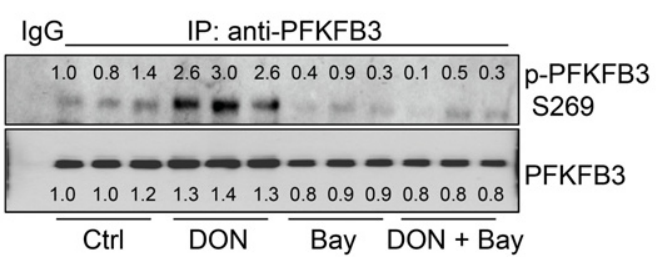

H



B

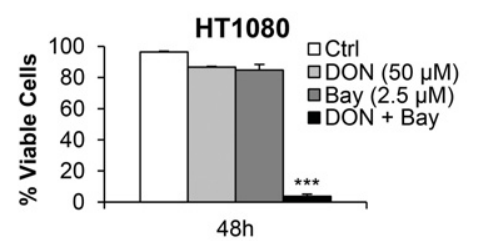

D

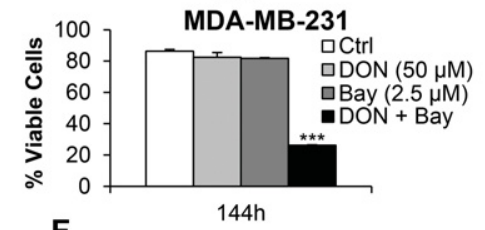

F
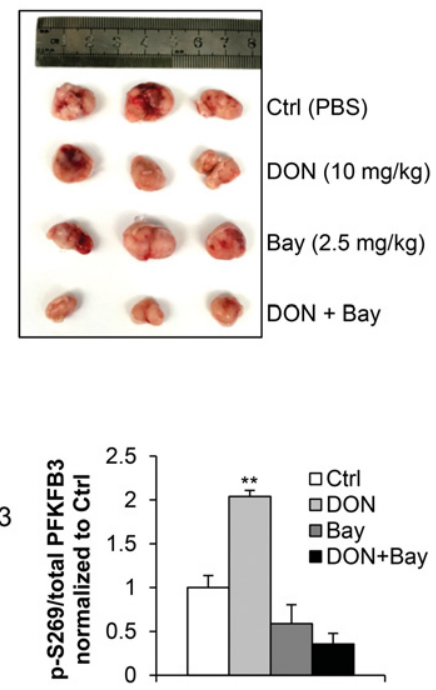

Figure 7. Inhibition of IKK $\beta$ sensitizes cancer cells and tumors to glutaminase inhibitor treatment. (A) HT1080 cells were cultured for $24 \mathrm{~h}$ in complete medium, complete medium supplemented with $2.5 \mu \mathrm{M}$ Bay, glutamine-free medium, or glutamine-free medium supplemented with 2.5 $\mu \mathrm{M}$ Bay, and viability was assessed by propidium iodide exclusion. Data presented are mean \pm SEM of three independent experiments performed in duplicate. $(B-D)$ HT1080, U251, or MDA-MB-231 cells were cultured complete medium supplemented with PBS (control [Ctrl]), $50 \mu \mathrm{M}$ DON, Bay (as indicated), or the combination of DON and Bay for indicated time points, and viability was assessed by propidium iodide exclusion. Data presented are mean \pm SEM of three independent experiments performed in duplicate. (E) Athymic (nude) mice were injected subcutaneously with $2 \times 10^{6} \mathrm{HT} 1080$ cells. Mice were then placed into four groups and treated with control (PBS), $10 \mathrm{mg} / \mathrm{kg}$ DON, $2.5 \mathrm{mg} / \mathrm{kg}$ Bay, or the combination of $10 \mathrm{mg} / \mathrm{kg}$ DON and 2.5 $\mathrm{mg} / \mathrm{kg}$ Bay three times per week for $2 \mathrm{wk}$, and tumor growth was measured over time. Data presented are mean $\pm \mathrm{SD}$ of eight tumors per group. $(F, G)$ HT1080 xenograft tumors were harvested and photographed, followed by lysis and immunoprecipitation with anti-PFKFB3 antibody and immunoblotting with the indicated antibodies. Immunoblots were quantified using ImageJ, and the graph represents the mean of each group p-Ser269 divided by the total PFKFB3 normalized to the control treatment values. $(H)$ Paraffin-embedded tissues were deparaffinized and stained with p-Ser269 PFKFB3 antibody followed by counterstaining with hematoxylin. Images were acquired using a Zeiss Observer II microscope. Bar, $100 \mu \mathrm{m}$. $\left(^{*}\right) P<0.05 ;\left({ }^{* *}\right) P<0.01 ;\left(^{* * *}\right) P<0.005$, Student's $t$-test. 
Although IKK $\beta$ is most well known as an initiator of NF- $\kappa \mathrm{B}$ transcription, we found little effect of NF- $\kappa \mathrm{B}$ on low-glutamine-induced cell survival. Although we did observe p65 Ser536 phosphorylation in response to glutamine withdrawal, we found no significant increase in p65 trans-activity (Fig. 1; Supplemental Fig. S1). This is not entirely surprising, as p65 Ser536 phosphorylation does not necessarily affect p65 transcriptional activity (Okazaki et al. 2003). Interestingly, previous reports have indicated that glutamine level affects LPS or interleukin $1-\beta$ function via modulation of p 65 nuclear activity (Liboni et al. 2005; Brasse-Lagnel et al. 2007), indicating that glutamine level may play a role in coordinating cytokine-regulated NF- $\mathrm{kB}$ activity and cell survival.

In recent years, several reports have demonstrated that $\operatorname{IKK} \beta$ is a diverse kinase that phosphorylates numerous other substrates, such as the p85a subunit of PI3K, TSC1, BAD, and $\beta$-Catenin (Lamberti et al. 2001; Lee et al. 2007; Comb et al. 2012; Yan et al. 2013). More recently, a high-throughput screen combining quantitative MS with random forest bioinformatics to dissect the TNFa-IKK $\beta$-induced phosphoproteome in MCF-7 breast cancer cells revealed dozens of potential IKK $\beta$ substrates (Krishnan et al. 2015). Of significance, PFKFB3 phosphorylation was identified in this study, providing independent confirmation that PFKFB3 is a putative IKK $\beta$ substrate. Interestingly, IKK $\beta$ phosphorylation of its substrates often marks them for degradation via the SCF $\beta$ TRCP-ubiquitin ligase complex (Winston et al. 1999), and PFKFB3 is reportedly regulated by the SCF $\beta-T R C P-$ ubiquitin ligase complex, which requires phosphorylation at Ser269 (Colombo et al. 2011; Duan and Pagano 2011). Consistently, we found that the PFKFB3 protein level is reduced upon glutamine deprivation in an IKK $\beta$-dependent manner (Fig. 3I, input). Moreover, we found the unphosphorylateable form of PFKFB3 (S269A mutant) to be much more stable in cells (Fig. 4F). Interestingly, we found that PFKFB3 Ser269 phosphorylation also affects its activity (Fig. 4D). Although the observed increase in PFKFB3 activity of S269A mutant could be explained by protein level, the expression of wild-type and S269D mutant PFKFB3 is similar, yet the activity of the S269D mutant is $80 \%$ reduced. Ser269 is located in a highly disordered region critical for PFKFB3 enzyme function, as the nearby residues must remain in contact with two-phosphate oxygens and help stabilize a tele-phosphohistidine intermediate (Cavalier et al. 2012; Boyd et al. 2015); therefore, phosphorylation could disrupt these interactions and normal function, which could ultimately decrease the activity. Taken together, our data suggest a dual consequence of IKK $\beta$-dependent phosphorylation of PFKFB3 Ser269: (1) acutely reducing its activity and (2) marking it for ubiquitin-mediated degradation. Further studies will examine whether the SCF $\beta$-TRCP-ubiquitin ligase complex is active in response to low-glutamine-induced metabolic stress. It is worth mentioning that, although other PFKFB3 phosphosites were identified using MS, we believe that Ser269 is the major site that is regulated by IKK $\beta$ due to the highly conserved IKK $\beta$ phospho-motif and the almost complete reduction in phosphorylation of the PFKFB3 S269A mutant (Fig. 3F).

The finding of the IKK $\beta$-PFKFB3 signaling axis may be important in many other biological contexts. For example, it has been reported that constitutively active IKK $\beta$ in hepatocytes leads to hyperglycemia and insulin resistance, and inhibition of PFKFB3 also leads to insulin resistance in mice (Cai et al. 2005; Huo et al. 2010). These studies support our model in that active IKK $\beta$ will inhibit PFKFB3, which will decrease glucose uptake and glycolysis that can lead to hyperglycemia and insulin resistance. In addition, a dramatic shift toward aerobic glycolysis is observed when $\mathrm{CD}^{+} \mathrm{T}$ cells are proliferating, and a return to high oxidative phosphorylation (low glycolysis) occurs when activated $\mathrm{CD}^{+} \mathrm{T}$ cells become memory $\mathrm{T}$ cells (Gerriets et al. 2015), and T-reg cells rarely exhibit high aerobic glycolysis and generally maintain high oxidative phosphorylation (Beier et al. 2015). Of particular interest, a study conducted using $\mathrm{CD} 4^{+} \mathrm{T}$-cell-specific IKK $\beta$ knockout mice found that IKK $\beta$-deficient mice had dramatically less memory $\mathrm{T}$ cells and almost no T-reg cells, suggesting an inability to down-regulate aerobic glycolysis (SchmidtSupprian et al. 2003). Therefore, it will be interesting to examine the IKK $\beta$-PFKFB3 axis in these contexts as well as others where IKK $\beta$ activation occurs.

In this study, we also demonstrated the potential for targeting IKK $\beta$ in combination with glutamine metabolism inhibition. The finding that cancer cells are addicted to glutamine led to therapeutic approaches aimed at impairing glutamine metabolism. For example, glutaminase inhibitors DON or bis-2-[5-(phenylacetamido)-1,3,4-thiadiazol-2-yl]ethyl sulfide (BPTES) significantly diminish tumor growth in vivo (Kisner et al. 1980; Beier et al. 2015; Hernandez-Davies et al. 2015; Xiang et al. 2015). However, this approach will inevitably trigger metabolic stress and the adaptive response in cancer cells. We found that PFKFB3 is phosphorylated at Ser269 in tumors and even higher in tumors treated with glutamine deprivation-mimicking glutaminase inhibitor (DON) (Fig. 7C). Interestingly, DON-induced PFKFB3 Ser269 phosphorylation was blocked when coadministered with Bay, and these tumors grew at a significantly slower rate than those treated with DON or Bay alone, suggesting that PFKFB3 Ser269 phosphorylation is important for tumorigenesis (Fig. 7E). Thus, by eliminating IKK $\beta$-dependent PFKFB3 inhibition, cancer cells are unable to adapt and are more susceptible to glutaminase inhibitor treatment. Strikingly, we found that multiple types of cancer cells are synergistically killed when IKK $\beta$ and glutaminase inhibitors are combined and observed PFKFB3 Ser269 phosphorylation in several human malignancies, providing proof of concept that combinational targeting could provide a new therapeutic option for cancer patients.

\section{Materials and methods}

Reagents and plasmids

Recombinant active GST- IKK $\beta$ (31176) was purchased from Active Motif. Recombinant GST-IкBa (I20-30G), GST-PFKFB3 
(P323-30G), GST-PFKFB3 S269A (custom order), and GSTPFKFB4 (P324-30G) were purchased from SignalChem. Recombinant GST-c-JUN (GLO127G) was purchased from GloboZymes. and adenosine $5^{\prime}$-triphosphate, $[\gamma$-32P]-(BLU5024) was purchased from PerkinElmer. Bay (10010266) and TPCA-1 (15115) were purchased from Cayman Chemical. 6-dizao-5-oxo-L-norleucine (D2141), dimethyl succinate (W239607CSBOLDSTART),CSBOLDEND and NAC (138061) were purchased from Sigma. LPS serotype 0111:B4 (ALX-581-012-L001) was purchased from Enzo Life Sciences. GSH monoethyl ester (353905) was purchased from Calbiochem. pLX304 (25890), pLPC-N-Flag (12521), pLKO.1-Scramble (1864), pCMV2-Flag-IKK $\beta$ (11103), pCMV2-Flag-IKK $\beta$ kinase inactive (11104), and pBabe-Puro-IKB $\alpha$-mut (15291) were purchased from Addgene. pLX304-PFKFB3 was purchased from Thermo-Dharmacon. pLX304-PFKFB3 S269A and S269D mutants were generated by MCLab. TRC human p65 shRNA (TRCN0000014686), TRC human IKK $\beta$ shRNA (TRCN0000 018917), and TRC human PFKFB3 shRNA (TRCN0000007338) plasmids were purchased from Thermo-Dharmacon.

\section{Cell lines and cell culture}

293T, HT1080, MCF-7, HeLa, and MDA-MB-231 cells were purchased from American Type Culture Collection (ATCC). Wildtype, Ikk $\alpha^{-/}$, and $I k k \beta^{-/-}$MEFs were kindly provided by Dr. Michael Karin's laboratory (University of California at San Diego). Wild-type and $p 65^{-/-}$MEFs were a gift from Dr. Hua Yu's laboratory (City of Hope Cancer Center). U251 cells were kindly provided by Dr. Craig Thompson's laboratory (Sloan Kettering Cancer Center). HT1080 cells expressing shRNA against p65, IKK $\beta$, and/or PFKFB3 were generated via lentiviral-mediated gene transfer followed by puromycin selection and limited dilution to generate clonal cell lines. Wild-type MEFs ectopically expressing superrepressive IкBa were generated via retroviral-mediated gene transfer followed by puromycin selection. HT1080 cells ectopically expressing V5 wild-type, V5-S269A, or V5-S269D PFKFB3 were generated via lentiviral-mediated gene transfer followed by blasticidin selection. All cells were cultured in Dulbecco's modified Eagle's medium (DMEM) containing $25 \mathrm{mM}$ glucose and $4 \mathrm{mM}$ L-glutamine supplemented with $10 \%$ fetal bovine serum (FBS) (Gemini Bio-Products), $100 \mathrm{U} / \mathrm{mL}$ penicillin, and $100 \mu \mathrm{g} / \mathrm{mL}$ streptomycin. For glutamine starvation experiments, DMEM without glutamine (Invitrogen, 11960) was supplemented with $10 \%$ dialyzed FBS (Gemini Bio-Products). For starvation experiments, cells cultured in complete medium were supplemented with $10 \%$ dialyzed FBS /Gemini Bio-Products). Cell death was determined using propidium iodide exclusion flow cytometry.

\section{siRNA transfection}

On-target Smart Pool control siRNA (D-001810-10-20) and siRNA oligonucleotides targeting human p65 (L-003533-000005), human IKK $\beta$ (L-003503-00-0005), and human GLUT3 (L007516-02-0005) were obtained from Thermo-Dharmacon. siRNA transfections were performed using Lipofectamine RNAiMAX (Invitrogen) according to the manufacturer's protocol.

\section{Immunoblotting}

Cells were lysed in buffer (50 mM Tris- $\mathrm{HCl}$ at $\mathrm{pH} 7.4,5 \mathrm{mM}$ sodium fluoride, $5 \mathrm{mM}$ sodium pyrophosphate, $1 \mathrm{mM}$ EDTA, 1 mM EGTA, $250 \mathrm{mM}$ mannitol, 1\% [v/v] Triton X-100) containing freshly added protease inhibitor complex (Roche) and phosphatase inhibitor (Thermo Scientific). Equal amounts of protein
(10-30 $\mu \mathrm{g}$ ) were loaded onto precast NuPAGE Bis-Tris gels (Life Technologies) followed by transfer onto nitrocellulose. The Thermo Scientific NE-PER nuclear and cytoplasmic extraction kit was used for cellular fractionation according to the manufacturer's guidelines. Immunoblotting was performed with the following antibodies: IKK $\beta$ (Cell Signaling), IKKa (Cell Signaling), p-IKK $\beta$ Ser177 and p-IKKa Ser176 (Cell Signaling), p65 (Cell Signaling), p-p65 (Cell Signaling), IкB (Cell Signaling), V5 (Cell Signaling), $\beta$-Actin (Sigma), Flag M2 (Sigma), Tubulin (Sigma), Lamin B1 (Novus Biologicals), and PFKFB3 (Proteintech). pPFKFB3 Ser269 was generated by Abiocode using the antigen "LGGRIGGD-pS-GLSSR" followed by affinity purification of crude antiserum.

\section{Immunoprecipitation}

For coimmunoprecipitation, one $10-\mathrm{cm}$ plate containing cells grown to $80 \%$ confluence was used for each treatment condition and divided into aliquots for different immunoprecipitation conditions or antibodies. To harvest, cells were washed twice on the plate with PBS and lysed on ice using a cell scraper with lysis buffer $(150 \mathrm{mM} \mathrm{KCl}, 0.2 \%$ [v/v] NP-40, 10\% [v/v] glycerol, $20 \mathrm{mM}$ Tris at $\mathrm{pH} 7.5,0.5 \mathrm{mMDTT}$ ) containing freshly added protease inhibitor complex (Roche) and phosphatase inhibitor (Thermo Scientific), and protein quantification was performed using a BCA assay (Pierce). Equal amounts of lysate (500 $\mu \mathrm{g}$ to $1 \mathrm{mg}$ ) were immunoprecipitated while rotating at $4^{\circ} \mathrm{C}$ with $4 \mu \mathrm{g}$ of one of the following antibodies: V5 (Cell Signaling), PFKFB3 (anti-mouse; Abnova), or control IgG mouse (Sigma). Protein G agarose (20 $\mu \mathrm{L})$ or anti-Flag-conjugated agarose $(20 \mu \mathrm{L})$ beads were added to each immunoprecipitate and rotated for $24 \mathrm{~h}$. Beads were washed four times with lysis buffer, resuspended in SDS loading dye, and boiled prior to immunoblotting. For PFKFB3 immunoprecipitation followed by p-Ser269 immunoblotting, cells were lysed in the immunoblotting buffer.

\section{Immunofluorescence and immunohistochemistry}

Immunofluorescence staining was performed as described previously (Rosales et al. 2015). Cells were starved of glutamine for $24 \mathrm{~h}$ prior to staining with 1:75 diluted anti-IKK $\beta$ (Novus Biologicals 10AG2) and 1:300 diluted anti-PFKFB3 (OriGene TA590185) antibodies. Nuclei were visualized by staining with $1 \mu \mathrm{g} / \mathrm{mL}$ DAPI. Images were captured using a Zeiss LSM 700 confocal (immunofluorescence) or Zeiss Observer II (immunohistochemistry) microscope at 20x objective and analyzed using Zen 2012 software. Immunohistochemistry was performed as described previously (Fong et al. 2015) using $10 \mathrm{mM}$ Tris- $\mathrm{HCl}, 1 \mathrm{mM}$ EDTA, and $0.05 \%$ Tween-20 (pH 9.0) retrieval buffer. p-PFKFB3 Ser 269 antibody was used at 1:100 dilution. Tissue arrays were purchased from US Biomax (brain BS17016a, breast BC08013a, and skin BC21014)

\section{Quantitative real-time PCR}

Total RNA was extracted using Trizol (Invitrogen) and purified according to the manufacturer's guidelines. One microgram of RNA was added as a template to reverse transcriptase reactions carried out using the qScript cDNA synthesis kit (Quanta Biosciences). Quantitative real-time PCRs were carried out with the resulting cDNAs using SYBR Green PCR master mix (Quanta Biosciences) using an iQ5 real-time PCR machine (Biorad) with the following primers: 18S-F (5'-CCCGTTGAACCCCATTC GTGA-3'), 18S-R (5'-GCCTCACTAAACCATCCAATCGG-3'), 
GLUT3-F (5'-CAACTTCATGTCAACTTCTGGCT-3'), and GL UT3-R (5'-CTCAGTGAGAAATGGGACCCT-3').

\section{PFKFB3 activity assays}

PFKFB3 activity was assayed using the Biovision, Inc. (K776-100), phosphofructokinase activity colorimetric assay kit according to the manufacturer's guidelines. Briefly, cells were seeded to $80 \%$ confluence followed by lysis using the provided lysis buffer. Cells were then spun down, and the supernatant was subjected to a 10$\mathrm{KD}$ spin column to remove interfering small molecules. Lysates were the quantified, and $50 \mu \mathrm{g}$ of protein was used per reaction.

\section{Glucose/glutamine uptake and lactate production measurements}

Cells were seeded at $1 \times 10^{5}$ cells per well into a six-well plate, and, the following day, medium was aspirated and replaced with $1 \mathrm{~mL}$ of fresh DMEM. Twenty-four hours later, medium was collected and measured using the Nova Biomedical BioProfile 100 plus machine. Cells were counted, and all metabolite measurements were then normalized per cell.

\section{Seahorse assays}

ECAR of cells was measured with the Searhorse Bioscience XF24 extracellular flux analyzer. Briefly, $5 \times 10^{4}$ cells per well were seeded in $525 \mu \mathrm{L}$ of XF assay medium supplemented with 2 $\mathrm{mM}$ glutamine. Cells were incubated in $\mathrm{a} \mathrm{CO}_{2}$-free incubator for $1 \mathrm{~h}$ at $37^{\circ} \mathrm{C}$ to allow for temperature and $\mathrm{pH}$ equilibration prior to loading into the XF24 apparatus. XF assays consisted of sequential $\mathrm{mix}$ ( $3 \mathrm{~min})$, pause $(3 \mathrm{~min})$, and measurement $(5 \mathrm{~min})$ cycles, allowing for determination of ECAR every $10 \mathrm{~min}$.

\section{Kinase assays}

Recombinant active GST-IKK $\beta$ or immunoprecipitated Flag-IKK $\beta$ was incubated for $30 \mathrm{~min}$ at $30^{\circ} \mathrm{C}$ with kinase assay buffer (Cell Signaling), $200 \mu$ M ATP (10 mM stock; Cell Signaling), the specified recombinant GST-tagged proteins, and $1 \mu \mathrm{L}$ of $\left[\gamma^{-}{ }^{32} \mathrm{P}\right]$-ATP (10 mCi per milliliter of stock) in a final volume of $30 \mu \mathrm{L}$. The reaction was quenched by adding $10 \mu \mathrm{L}$ of SDS loading dye, and reactions were separated by SDS-PAGE and exposed to autoradiograph film for $15 \mathrm{~min}$ to $1 \mathrm{~h}$. For cold kinase assays, all reaction conditions were the same except for the addition of $\left[\gamma^{-32} \mathrm{P}\right]$-ATP.

\section{${ }^{13} \mathrm{C}$-glucose tracing}

Cells were seeded in a 6 -cm plate at a density of $2 \times 10^{5}$ cells per dish. After overnight incubation, medium was removed, and cells were washed with $3 \mathrm{~mL}$ of PBS before the addition of glucose-free DMEM supplemented with $10 \%$ dialyzed and heat-inactivated FBS and $25 \mathrm{mM}{ }^{13} \mathrm{C}$-glucose (Cambridge Isotope Laboratory). After $6 \mathrm{~h}$ of incubation, the cells were harvested, and the metabolites were extracted as described previously (Liu et al. 2015). ${ }^{13} \mathrm{C}$ metabolite measurements were determined using LC-HR-MS as described previously (Liu et al. 2015).

\section{NADPH measurement}

Cells were cultured for $24 \mathrm{~h}$ in complete medium and then measured using the NADP/NADPH-Glo kit (Promega, G9081) according to the manufacturer's guidelines.

\section{Mouse xenografts}

All studies involving animals were performed according to approved IACUC protocols at the City of Hope Cancer Center. In brief, $2 \times 10^{6}$ HT1080 cells were resuspended in $200 \mu \mathrm{L}$ of DMEM, and tumors were established subcutaneously in 10-wkold male athymic mice (Taconic). Mice were then placed into four groups and treated with PBS, $10 \mathrm{mg} / \mathrm{kg}$ DON, $2.5 \mathrm{mg} / \mathrm{kg}$ Bay, or the combination of $10 \mathrm{mg} / \mathrm{kg}$ DON and $2.5 \mathrm{mg} / \mathrm{kg}$ Bay three times per week for $2 \mathrm{wk}$, and tumor growth was measured over time using the formula $1 / 2$ (length $\times$ width $^{2}$ ).

\section{Statistics}

Results are shown as means; error bars represent the standard error of the mean or standard deviation as indicated. The unpaired Student's $t$-test was used to determine the statistical significance of differences between means $\left(P<0.05\left[{ }^{*}\right], P<0.01\left[{ }^{* *}\right]\right.$, and $P<$ $0.005[* * *])$.

\section{Acknowledgments}

We thank members of the Kong laboratory for helpful comments on the manuscript. We thank Ross Tomaino at the Harvard Mass Spectrometry Core for assisting in the protein mass spectrometric peptide sequencing and phosphopeptide mapping experiments. Research is supported by National Institutes of Health/ National Cancer Institute 1R01CA183989-01A1. M.A.R. is supported by the Ralph M. Parsons Foundation. M.K. is the Pew Scholar in the Biomedical Sciences, V Scholar in Cancer Research, and American Cancer Society Research Scholar. X.H.L. is supported by DNA Damage Response and Oncogenic Signaling (DDROS) Training Program at City of Hope. Research reported here includes work performed in Core Facilities supported by the National Institutes of Health/National Cancer Institute under grant number P30CA33572.

\section{References}

Almeida A, Bolanos JP, Moncada S. 2010. E3 ubiquitin ligase APC/C-Cdh1 accounts for the Warburg effect by linking glycolysis to cell proliferation. Proc Natl Acad Sci 107: 738-741.

Atsumi T, Chesney J, Metz C, Leng L, Donnelly S, Makita Z, Mitchell R, Bucala R. 2002. High expression of inducible 6phosphofructo-2-kinase/fructose-2,6-bisphosphatase (iPFK-2; PFKFB3) in human cancers. Cancer Res 62: 5881-5887.

Baspinar A, Cukuroglu E, Nussinov R, Keskin O, Gursoy A. 2014. PRISM: a Web server and repository for prediction of proteinprotein interactions and modeling their $3 \mathrm{D}$ complexes. Nucleic Acids Res 42: W285-W289.

Beier UH, Angelin A, Akimova T, Wang L, Liu Y, Xiao H, Koike MA, Hancock SA, Bhatti TR, Han R, et al. 2015. Essential role of mitochondrial energy metabolism in Foxp $3^{+} \mathrm{T}$-regulatory cell function and allograft survival. FASEB $J$ 29: 2315-2326.

Boroughs LK, DeBerardinis RJ. 2015. Metabolic pathways promoting cancer cell survival and growth. Nat Cell Biol 17: 351-359.

Boyd S, Brookfield JL, Critchlow SE, Cumming IA, Curtis NJ, Debreczeni J, Degorce SL, Donald C, Evans NJ, Groombridge S, et al. 2015. Structure-based design of potent and selective inhibitors of the metabolic kinase PFKFB3. J Med Chem 58: 3611-3625. 
Brasse-Lagnel C, Lavoinne A, Loeber D, Fairand A, Bole-Feysot C, Deniel N, Husson A. 2007. Glutamine and interleukin-1 $\beta$ interact at the level of $\mathrm{Sp} 1$ and nuclear factor- $\mathrm{\kappa B}$ to regulate argininosuccinate synthetase gene expression. FEBS I 274: 5250-5262.

Cai D, Yuan M, Frantz DF, Melendez PA, Hansen L, Lee J, Shoelson SE. 2005. Local and systemic insulin resistance resulting from hepatic activation of IKK- $\beta$ and NF-кB. Nat Med 11: 183-190.

Calvo MN, Bartrons R, Castano E, Perales JC, Navarro-Sabate A, Manzano A. 2006. PFKFB3 gene silencing decreases glycolysis, induces cell-cycle delay and inhibits anchorage-independent growth in HeLa cells. FEBS Lett 580: 3308-3314.

Cavalier MC, Kim SG, Neau D, Lee YH. 2012. Molecular basis of the fructose-2,6-bisphosphatase reaction of PFKFB3: transition state and the C-terminal function. Proteins 80: 1143-1153.

Colombo SL, Palacios-Callender M, Frakich N, Carcamo S, Kovacs I, Tudzarova S, Moncada S. 2011. Molecular basis for the differential use of glucose and glutamine in cell proliferation as revealed by synchronized HeLa cells. Proc Natl Acad Sci 108: 21069-21074.

Comb WC, Cogswell P, Sitcheran R, Baldwin AS. 2011. IKK-dependent, NF-кB-independent control of autophagic gene expression. Oncogene 30: 1727-1732.

Comb WC, Hutti JE, Cogswell P, Cantley LC, Baldwin AS. 2012. p85a SH2 domain phosphorylation by IKK promotes feedback inhibition of PI3K and Akt in response to cellular starvation. Mol Cell 45: 719-730.

Criollo A, Senovilla L, Authier H, Maiuri MC, Morselli E, Vitale I, Kepp O, Tasdemir E, Galluzzi L, Shen S, et al. 2010. The IKK complex contributes to the induction of autophagy. EMBO J 29: 619-631.

DeBerardinis RJ, Mancuso A, Daikhin E, Nissim I, Yudkoff M, Wehrli S, Thompson CB. 2007. Beyond aerobic glycolysis: transformed cells can engage in glutamine metabolism that exceeds the requirement for protein and nucleotide synthesis. Proc Natl Acad Sci 104: 19345-19350.

DeBerardinis RJ, Lum JJ, Hatzivassiliou G, Thompson CB. 2008. The biology of cancer: metabolic reprogramming fuels cell growth and proliferation. Cell Metab 7: 11-20.

Domenech E, Maestre C, Esteban-Martinez L, Partida D, Pascual R, Fernandez-Miranda G, Seco E, Campos-Olivas R, Perez M, Megias D, et al. 2015. AMPK and PFKFB3 mediate glycolysis and survival in response to mitophagy during mitotic arrest. Nat Cell Biol 17: 1304-1316.

Duan S, Pagano M. 2011. Linking metabolism and cell cycle progression via the APC/CCdh1 and SCF $\beta$ TrCP ubiquitin ligases. Proc Natl Acad Sci 108: 20857-20858.

Earhart RH, Amato DI, Chang AY, Borden EC, Shiraki M, Dowd ME, Comis RL, Davis TE, Smith TJ. 1990. Phase II trial of 6diazo-5-oxo-L-norleucine versus aclacinomycin-A in advanced sarcomas and mesotheliomas. Invest New Drugs 8: $113-119$.

Fong MY, Zhou W, Liu L, Alontaga AY, Chandra M, Ashby J, Chow A, O'Connor ST, Li S, Chin AR, et al. 2015. Breast-cancer-secreted miR-122 reprograms glucose metabolism in premetastatic niche to promote metastasis. Nat Cell Biol 17: 183-194.

Gao P, Tchernyshyov I, Chang TC, Lee YS, Kita K, Ochi T, Zeller KI, De Marzo AM, Van Eyk JE, Mendell JT, et al. 2009. c-Myc suppression of miR-23a/b enhances mitochondrial glutaminase expression and glutamine metabolism. Nature 458: 762-765.
Gerriets VA, Kishton RJ, Nichols AG, Macintyre AN, Inoue M, Ilkayeva O, Winter PS, Liu X, Priyadharshini B, Slawinska $\mathrm{ME}$, et al. 2015. Metabolic programming and PDHK1 control $\mathrm{CD}^{+} \mathrm{T}$ cell subsets and inflammation. $J$ Clin Invest 125: 194-207.

Gloire G, Charlier E, Rahmouni S, Volanti C, Chariot A, Erneux C, Piette J. 2006. Restoration of SHIP-1 activity in human leukemic cells modifies NF- $\mathrm{kB}$ activation pathway and cellular survival upon oxidative stress. Oncogene 25: 5485-5494.

Hernandez-Davies JE, Tran TQ, Reid MA, Rosales KR, Lowman XH, Pan M, Moriceau G, Yang Y, Wu J, Lo RS, et al. 2015. Vemurafenib resistance reprograms melanoma cells towards glutamine dependence. I Transl Med 13: 210.

Huo Y, Guo X, Li H, Wang H, Zhang W, Wang Y, Zhou H, Gao Z, Telang S, Chesney J, et al. 2010. Disruption of inducible 6phosphofructo-2-kinase ameliorates diet-induced adiposity but exacerbates systemic insulin resistance and adipose tissue inflammatory response. I Biol Chem 285: 3713-3721.

Kaadige MR, Looper RE, Kamalanaadhan S, Ayer DE. 2009. Glutamine-dependent anapleurosis dictates glucose uptake and cell growth by regulating MondoA transcriptional activity. Proc Natl Acad Sci 106: $14878-14883$.

Kamphorst JJ, Nofal M, Commisso C, Hackett SR, Lu W, Grabocka E, Vander Heiden MG, Miller G, Drebin JA, Bar-Sagi D, et al. 2015. Human pancreatic cancer tumors are nutrient poor and tumor cells actively scavenge extracellular protein. Cancer Res 75: 544-553.

Kawauchi K, Araki K, Tobiume K, Tanaka N. 2008. p53 regulates glucose metabolism through an IKK-NF- $\mathrm{kB}$ pathway and inhibits cell transformation. Nat Cell Biol 10: 611-618.

Kisner DL, Catane R, Muggia FM. 1980. The rediscovery of DON (6-diazo-5-oxo-L-norleucine). Recent Results Cancer Res 74: 258-263.

Krishnan RK, Nolte H, Sun T, Kaur H, Sreenivasan K, Looso M, Offermanns S, Kruger M, Swiercz JM. 2015. Quantitative analysis of the TNF- $\alpha$-induced phosphoproteome reveals AEG-1/ MTDH/LYRIC as an IKK $\beta$ substrate. Nat Commun 6: 6658.

Lamberti C, Lin KM, Yamamoto Y, Verma U, Verma IM, Byers S, Gaynor RB. 2001. Regulation of $\beta$-catenin function by the IкB kinases. J Biol Chem 276: 42276-42286.

Le A, Lane AN, Hamaker M, Bose S, Gouw A, Barbi J, Tsukamoto T, Rojas CJ, Slusher BS, Zhang H, et al. 2012. Glucose-independent glutamine metabolism via TCA cycling for proliferation and survival in B cells. Cell Metab 15: 110-121.

Lee DF, Kuo HP, Chen CT, Hsu JM, Chou CK, Wei Y, Sun HL, Li LY, Ping B, Huang WC, et al. 2007. IKK $\beta$ suppression of TSC1 links inflammation and tumor angiogenesis via the mTOR pathway. Cell 130: 440-455.

Liboni KC, Li N, Scumpia PO, Neu J. 2005. Glutamine modulates LPS-induced IL-8 production through IкB/NF- $\kappa B$ in human fetal and adult intestinal epithelium. J Nutr 135: 245-251.

Lin R, Beauparlant P, Makris C, Meloche S, Hiscott J. 1996. Phosphorylation of IkBa in the C-terminal PEST domain by casein kinase II affects intrinsic protein stability. Mol Cell Biol 16: 1401-1409.

Liu X, Sadhukhan S, Sun S, Wagner GR, Hirschey MD, Qi L, Lin H, Locasale JW. 2015. High-resolution metabolomics with Acyl-CoA profiling reveals widespread remodeling in response to diet. Mol Cell Proteomics 14: 1489-1500.

Lunt SY, Vander Heiden MG. 2011. Aerobic glycolysis: meeting the metabolic requirements of cell proliferation. Annu Rev Cell Dev Biol 27: 441-464.

Mauro C, Leow SC, Anso E, Rocha S, Thotakura AK, Tornatore L, Moretti M, De Smaele E, Beg AA, Tergaonkar V, et al. 2011. NF- $\kappa B$ controls energy homeostasis and metabolic adaptation 
by upregulating mitochondrial respiration. Nat Cell Biol 13: 1272-1279.

Oeckinghaus A, Hayden MS, Ghosh S. 2011. Crosstalk in NF-кB signaling pathways. Nat Immunol 12: 695-708.

Okazaki T, Sakon S, Sasazuki T, Sakurai H, Doi T, Yagita H, Okumura K, Nakano H. 2003. Phosphorylation of serine 276 is essential for p65 NF-kB subunit-dependent cellular responses. Biochem Biophys Res Commun 300: 807-812.

Polley S, Huang DB, Hauenstein AV, Fusco AJ, Zhong X, Vu D, Schrofelbauer B, Kim Y, Hoffmann A, Verma IM, et al. 2013. A structural basis for I $\mathrm{KB}$ kinase 2 activation via oligomerization-dependent trans auto-phosphorylation. PLOS Biol 11: e1001581.

Qing G, Li B, Vu A, Skuli N, Walton ZE, Liu X, Mayes PA, Wise DR, Thompson CB, Maris JM, et al. 2012. ATF4 regulates MYC-mediated neuroblastoma cell death upon glutamine deprivation. Cancer Cell 22: 631-644.

Reid MA, Wang WI, Rosales KR, Welliver MX, Pan M, Kong M. 2013. The B55a subunit of PP2A drives a p53-dependent metabolic adaptation to glutamine deprivation. Mol Cell 50: 200-211.

Ren J, Chen X, Chen ZJ. 2014. IKK $\beta$ is an IRF5 kinase that instigates inflammation. Proc Natl Acad Sci 111: 17438-17443.

Roberts E, Frankel S. 1949. Free amino acids in normal and neoplastic tissues of mice as studied by paper chromatography. Cancer Res 9: 645-648.

Ros S, Santos CR, Moco S, Baenke F, Kelly G, Howell M, Zamboni N, Schulze A. 2012. Functional metabolic screen identifies 6phosphofructo-2-kinase/fructose-2,6-biphosphatase 4 as an important regulator of prostate cancer cell survival. Cancer Discov 2: 328-343.

Rosales KR, Reid MA, Yang Y, Tran TQ, Wang WI, Lowman X, Pan M, Kong M. 2015. TIPRL inhibits protein phosphatase 4 activity and promotes H2AX phosphorylation in the DNA damage response. PLoS One 10: e0145938.

Sakakibara R, Kato M, Okamura N, Nakagawa T, Komada Y, Tominaga N, Shimojo M, Fukasawa M. 1997. Characterization of a human placental fructose-6-phosphate, 2-kinase/ fructose-2,6-bisphosphatase. J Biochem 122: 122-128.

Schmidt-Supprian M, Courtois G, Tian J, Coyle AJ, Israel A, Rajewsky K, Pasparakis M. 2003. Mature T cells depend on signaling through the IKK complex. Immunity 19: 377-389.

Schoonbroodt S, Ferreira V, Best-Belpomme M, Boelaert JR, Legrand-Poels S, Korner M, Piette J. 2000. Crucial role of the amino-terminal tyrosine residue 42 and the carboxyl-terminal PEST domain of $\mathrm{I} \mathrm{B} a$ in NF- $\mathrm{kB}$ activation by an oxidative stress. J Immunol 164: 4292-4300.

Schoors S, De Bock K, Cantelmo AR, Georgiadou M, Ghesquiere B, Cauwenberghs S, Kuchnio A, Wong BW, Quaegebeur A, Goveia J, et al. 2014. Partial and transient reduction of glycolysis by PFKFB3 blockade reduces pathological angiogenesis. Cell Metab 19: 37-48.

Storz P, Toker A. 2003. Protein kinase D mediates a stressinduced NF- $\mathrm{kB}$ activation and survival pathway. EMBO J 22: 109-120.
Storz P, Doppler H, Toker A. 2004. Protein kinase C $\delta$ selectively regulates protein kinase D-dependent activation of NF- $\mathrm{kB}$ in oxidative stress signaling. Mol Cell Biol 24: 2614-2626.

Sullivan MP, Nelson JA, Feldman S, Van Nguyen B. 1988. Pharmacokinetic and phase I study of intravenous DON (6-diazo5-oxo-L-norleucine) in children. Cancer Chemother Pharmacol 21: 78-84.

Takada Y, Mukhopadhyay A, Kundu GC, Mahabeleshwar GH, Singh S, Aggarwal BB. 2003. Hydrogen peroxide activates NF- $\kappa \mathrm{B}$ through tyrosine phosphorylation of IкB $\alpha$ and serine phosphorylation of p65: evidence for the involvement of IкBa kinase and Syk protein-tyrosine kinase. I Biol Chem 278: 24233-24241.

Tuncbag N, Gursoy A, Nussinov R, Keskin O. 2011. Predicting protein-protein interactions on a proteome scale by matching evolutionary and structural similarities at interfaces using PRISM. Nat Protoc 6: 1341-1354.

Vander Heiden MG, Cantley LC, Thompson CB. 2009. Understanding the Warburg effect: the metabolic requirements of cell proliferation. Science 324: 1029-1033.

Van Schaftingen E, Hue L, Hers HG. 1980. Fructose 2,6-bisphosphate, the probably structure of the glucose- and glucagonsensitive stimulator of phosphofructokinase. Biochem I 192: 897-901.

Van Schaftingen E, Jett MF, Hue L, Hers HG. 1981. Control of liver 6-phosphofructokinase by fructose 2,6-bisphosphate and other effectors. Proc Natl Acad Sci 78: 3483-3486.

Winston JT, Strack P, Beer-Romero P, Chu CY, Elledge SJ, Harper

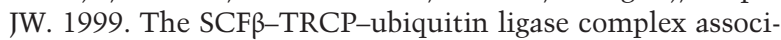
ates specifically with phosphorylated destruction motifs in I $\mathrm{B} \alpha$ and $\beta$-catenin and stimulates IкB $\alpha$ ubiquitination in vitro. Genes Dev 13: 270-283.

Wise DR, Thompson CB. 2010. Glutamine addiction: a new therapeutic target in cancer. Trends Biochem Sci 35: 427-433.

Wong MS, Raab RM, Rigoutsos I, Stephanopoulos GN, Kelleher JK. 2004. Metabolic and transcriptional patterns accompanying glutamine depletion and repletion in mouse hepatoma cells: a model for physiological regulatory networks. Physiol Genomics 16: 247-255.

Xiang Y, Stine ZE, Xia J, Lu Y, O'Connor RS, Altman BJ, Hsieh AL, Gouw AM, Thomas AG, Gao P, et al. 2015. Targeted inhibition of tumor-specific glutaminase diminishes cell-autonomous tumorigenesis. J Clin Invest 125: 2293-2306.

Yalcin A, Clem BF, Imbert-Fernandez Y, Ozcan SC, Peker S, O'Neal J, Klarer AC, Clem AL, Telang S, Chesney J. 2014. 6Phosphofructo-2-kinase (PFKFB3) promotes cell cycle progression and suppresses apoptosis via Cdk1-mediated phosphorylation of p27. Cell Death Dis 5: e1337.

Yamamoto T, Takano N, Ishiwata K, Ohmura M, Nagahata $Y$, Matsuura T, Kamata A, Sakamoto K, Nakanishi T, Kubo A, et al. 2014. Reduced methylation of PFKFB3 in cancer cells shunts glucose towards the pentose phosphate pathway. Nat Commun 5: 3480.

Yan J, Xiang J, Lin Y, Ma J, Zhang J, Zhang H, Sun J, Danial NN, Liu J, Lin A. 2013. Inactivation of BAD by IKK inhibits TNFainduced apoptosis independently of NF-kB activation. Cell 152: 304-315. 


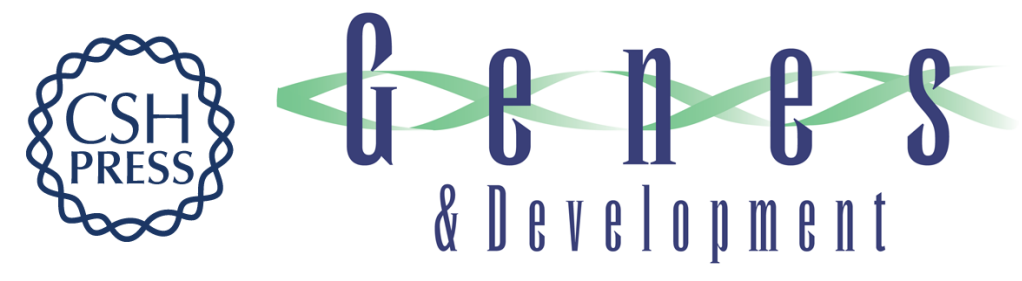

\title{
IKK $\beta$ promotes metabolic adaptation to glutamine deprivation via phosphorylation and inhibition of PFKFB3
}

\author{
Michael A. Reid, Xazmin H. Lowman, Min Pan, et al.
}

Genes Dev. 2016, 30: originally published online September 1, 2016

Access the most recent version at doi:10.1101/gad.287235.116

\section{Supplemental http://genesdev.cshlp.org/content/suppl/2016/08/29/gad.287235.116.DC1 Material}

References This article cites 66 articles, 24 of which can be accessed free at: http://genesdev.cshlp.org/content/30/16/1837.full.html\#ref-list-1

Creative This article is distributed exclusively by Cold Spring Harbor Laboratory Press for the first Commons six months after the full-issue publication date (see

License http://genesdev.cshlp.org/site/misc/terms.xhtml). After six months, it is available under a Creative Commons License (Attribution-NonCommercial 4.0 International), as described at http://creativecommons.org/licenses/by-nc/4.0/. Email Alerting
Service $\begin{aligned} & \text { Receive free email alerts when new articles cite this article - sign up in the box at the top } \\ & \text { right corner of the article or click here. }\end{aligned}$

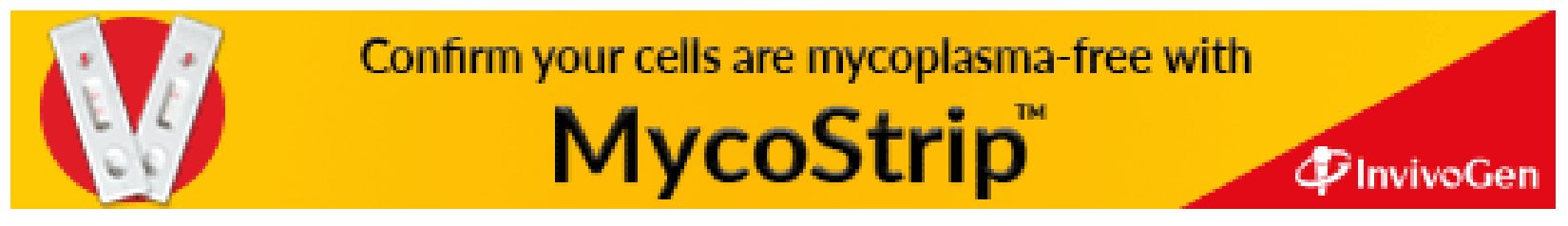

